\title{
pH-Controlled Liposomes for Enhanced Cell Penetration in Tumor Environment
}

\section{Barattin, Michela}

2018-05-30

Barattin , M , Mattarei , A, Balasso, A, Paradisi , C , Cantu , L , Del Favero, E, Viitala , T, Mastrotto , F , Caliceti , P \& Salmaso , S 2018 , ' pH-Controlled Liposomes for Enhanced Cell Penetration in Tumor Environment ' , ACS Applied Materials \& Interfaces , vol. 10 , no. 21 , pp. 17646-17661 . https://doi.org/10.1021/acsami.8b03469

http://hdl.handle.net/10138/327303

https://doi.org/10.1021/acsami.8b03469

unspecified

acceptedVersion

Downloaded from Helda, University of Helsinki institutional repository.

This is an electronic reprint of the original article.

This reprint may differ from the original in pagination and typographic detail.

Please cite the original version. 


\section{$\mathrm{pH}$-controlled liposomes for enhanced cell}

\section{penetration in tumor environment}

Michela Barattin, ${ }^{1}$ Andrea Mattarei, ${ }^{2,}$ Anna Balasso, ${ }^{1}$ Cristina Paradisi, ${ }^{2}$ Laura Cantù, ${ }^{3}$ Elena Del Favero, ${ }^{3}$ Tapani Viitala,${ }^{4}$ Francesca Mastrotto, ${ }^{1}$ Paolo Caliceti, ${ }^{1}$ Stefano Salmaso ${ }^{1 *}$

${ }^{1}$ Department of Pharmaceutical and Pharmacological Sciences, University of Padova, Via F. Marzolo 5, 35131 Padova, Italy; ${ }^{2}$ Department of Chemical Sciences, University of Padova, Via F. Marzolo 1, 35131 Padova, Italy; ${ }^{3}$ Department of Medical Biotechnologies and Traslational Medicine, University of Milano, LITA, Via F.1li Cervi, 93, 20090 Segrate, Italy; ${ }^{4}$ Centre for Drug Research and Division of Pharmaceutical Biosciences, Faculty of Pharmacy, University of Helsinki, Viikinkaari 5, P.O. Box 56, FI-00014, Helsinki, Finland; ${ }^{\S}$ author actual address: Department of Pharmaceutical and Pharmacological Sciences, University of Padova, Via F. Marzolo 5, 35131 Padova, Italy

KEYWORDS. pH-responsive liposomes, controlled cell uptake, cell penetration enhancers, sheddable liposome coating, site-selective drug delivery. 


\section{ABSTRACT}

An innovative $\mathrm{pH}$-switchable colloidal system that can be exploited for site-selective anticancer drug delivery has been generated by liposomes decoration with a new novel synthetic nonpeptidic oligo-Arginine cell-penetration enhancer (CPE) and a quenching PEGylated counterpart that detaches from the vesicle surface under the acidic conditions of tumors. The CPE module $\left(\operatorname{Arg}_{4}-D A G\right)$ is formed by four arginine units conjugated to a first generation $(\mathrm{G} 1)$ 2,2bis(hydroxymethyl)propionic acid (bis-MPA)/2,2-bis(aminomethyl)propionic acid (bis-AMPA) polyester dendron terminating with 1,2-distearoyl-3-azidopropane for liposome bilayer insertion. The zeta potential of the $\mathrm{Arg}_{4-} \mathrm{DAG}$-decorated liposomes increased up to $+32 \mathrm{mV}$ as the $\mathrm{Arg}_{4^{-}}$ $D A G$ /lipids molar ratio increased. The $\mathrm{Arg}_{4}-\mathrm{DAG}$ liposome shielding at $\mathrm{pH} 7.4$ was provided by methoxy-PEG5kDa-polymethacryloyl sulfadimethoxine $\left(\mathrm{mPEG}_{5 \mathrm{kDa}}-\mathrm{SDM}_{8}\right)$ with 7.1 apparent pKa. Zeta potential, surface plasmon resonance and synchrotron small-angle X-ray scattering analyses showed that at $\mathrm{pH} 7.4 \mathrm{mPEG}_{5 \mathrm{kDa}}-\mathrm{SDM}_{8}$ associates with polycationic $\operatorname{Arg}_{4}-D A G$-decorated liposomes yielding liposomes with neutral zeta potential. At $\mathrm{pH} 6.5$, which mimics the tumor environment, $\mathrm{mPEG}_{5 \mathrm{kDa}}-\mathrm{SDM}_{8}$ detaches from the liposome surface yielding $\mathrm{Arg}_{4}-\mathrm{DAG}$ exposure. Flow cytometry and confocal microscopy showed a 30-fold higher HeLa cancer cell association of the $\mathrm{Arg}_{4}-\mathrm{DAG}$-decorated liposomes compared to non-decorated liposomes. At pH 7.4, the $\mathrm{mPEG}_{5 \mathrm{kDa}}-\mathrm{SDM}_{8}$ coated liposomes undergo low cell association while remarkable cell association occurred at $\mathrm{pH} 6.5$, which allowed for the controlled intracellular delivery of model macromolecules and small molecules loaded in the liposome under tumor conditions. 


\section{INTRODUCTION}

New generation high-performance drug delivery colloidal systems have been developed to increase the tumor targeting and reduce off-target toxicity of chemotherapeutic agents. ${ }^{1-2}$ These systems are often designed to exploit the peculiar physio-pathological features at the tumor site to timely and spatially control the drug release. ${ }^{3-4}$

Targeting agents have been widely used to decorate drug nanocarriers for selective biorecognition of cells and intracellular delivery of therapeutic agents. However, biorecognition approaches may fail because tumor cell populations are extremely heterogeneous and expression levels of membrane targets can significantly vary. ${ }^{5-6}$ Furthermore, multivalent targeted nanocarriers may affect cellular receptor recycling efficiency during endocytosis, which limits further cargo internalization. ${ }^{7}$

A different approach for intracellular delivery of colloidal vehicles of anticancer drugs exploits cell penetration peptides (CPPs). Cell penetrating peptides, namely natural and synthetic TAT (transactivator of transcription)-derived peptides, ${ }^{8}$ have been exploited for intracellular delivery of a variety of colloidal cargoes, including proteins, oligonucleotides, nanovesicles and nanoparticles. ${ }^{9-10}$ Although a general consensus on the uptake mechanism of CPPs has not yet been achieved, two major cellular mechanisms of endocytic and non-endocytic pathways have been proposed. These mechanisms have been reported to depend on the transducing peptide sequences, the biophysical characteristics of the cargo and the cell type-dependent composition of the plasma membrane. ${ }^{11-12}$ However, high positive charge density resulting from protonation of the basic amino acid residues including arginine (Arg), lysine (Lys) and histidine (His) has been shown to be a structural requisite for CPP activity. Indeed, high positively charged amino 
acid sequences are engaged providing charge-to-charge interactions with anionic proteoglycans, in particular heparin sulfate proteoglycans (HSPGs), on the cell membrane corona. ${ }^{12}$ Brock et al reported that the cell up-take efficiency of CPPs increases with the decrease of the CPPs/HSPGs molar ratio and with the increase of the local Arg density in the peptide sequence. ${ }^{13-14}$

The guanidinium groups of Arg in the CPP sequences are structurally planar "Y" shaped molecules with delocalized positive charges, which allows for both electrostatic and hydrogen bonding with anionic and polar molecules. ${ }^{15}$ Accordingly, Arg interact through bi- or multidentate hydrogen bonds with anionic charges on the cell membrane surfaces, thus triggering saddle-splay curvature, which is correlated with the permeation ability of CPPs. On the other hand, protonated Lys is unable to promote the curvature in lipidic membranes and consequent cell penetration. ${ }^{12,16}$ Based on these evidences, guanidinium-rich synthetic analogues of the CPPs have been developed. ${ }^{12,15}$ It has been reported that the structural conformation of CPPs is not a prerequisite for their cell penetration activity even though the conformation dictates their penetration mechanism. CPPs that possess random conformation, such as TAT or Arg, undergo endocytic pathway rather than translocation, which is typical for CPPs with alfa-helix and betastrand conformations. Thus, the absence of a specific structural conformation of this class of cell penetration systems may be preferred when they are exploited for the delivery of macromolecular and colloidal cargoes and thus appealing for biomedical applications. ${ }^{17}$

Despite CPPs have extraordinary potential in the development of high performance drug delivery systems, they suffer from cell non-selectivity, thus yielding unspecific tissue association and random biodistribution, which represents a major drawback for their biomedical application for therapeutic purposes. Therefore, the use of CPPs for cell targeting requires dedicated molecular strategies to provide drug nanocarriers with site-selectivity. Furthermore, the use of these 
polypeptides is limited by their poor stability in biological environment due to proteolytic degradation. ${ }^{18-19}$ To overcome these limitations, we developed a stable novel non-peptide Arg based dendritic cell penetrating enhancer (CPE), tetraArg-[G-1]-distearoyl glycerol (Arg 4 -DAG) for liposomes decoration. Arg 4 -DAG contains a non-symmetrical dendritic scaffold based on 2,2-bis(hydroxyl-methyl)propionic acid (bis-MPA) building block that, on one side, terminates with oligo-cationic Arg with higher charge density than that found in natural linear CPPs, and, on the opposite side, with a hydrophobic tail to anchor the CPE to the liposome bilayer. In order to enable the $\operatorname{Arg}_{4}$-DAG decorated liposomes with tumor targeting behavior, the cationic charges were charge-to-charge quenched with a releasable PEGylating agent, $\mathrm{mPEG}_{5 \mathrm{kDa}}{ }^{-}$ oligomethacriloyl sulfadimethoxine $\left(\mathrm{mPEG}_{5 \mathrm{kDa}}-\mathrm{SDM}_{8}\right)$, which includes a $\mathrm{pH}$-sensitive polyanionic block. The $\mathrm{mPEG}_{5 \mathrm{kDa}}-\mathrm{SDM}_{8}$ coated $\mathrm{Arg}_{4}-\mathrm{DAG}$ decorated liposomes have been designed to bestow $\mathrm{pH}$-switchable liposomes. Under physiological conditions at $\mathrm{pH} 7.4$, namely in blood, the liposomes possess stealth features that minimize the association of the carrier to healthy cells. Under the acid environment of the tumor, ${ }^{4,20}$ the oligo-Arg moieties on the liposome surface are revealed upon $\mathrm{mPEG}_{5 \mathrm{kDa}}-\mathrm{SDM}_{8}$ detachment thus enhancing the association of the liposomes to cancer cells.

\section{EXPERIMENTAL SECTION}

\subsection{Materials and equipment}

Chemicals and equipment are reported in the electronic supplementary information (ESI). 


\subsection{Design and synthesis of the Cell Penetration Enhancer (CPE) module tetraArg-[G1]- distearoyl glycerol (Arg-DAG)}

First (G1) and second (G2) generation bis-MPA dendrons bearing 4 and 8 Arg, respectively, and functionalized with diacyl glycerol, were designed in silico by ChemDraw (PerkinElmer Inc.

Waltham, MA, USA). The structures underwent energy minimization using Force MMFF94x by Molecular Operating Environment (MOE) software (Chemical Computing Group Inc. Montreal, Canada). The data were elaborated assuming Arg monomers as dots centred on guanidinium carbon.

The synthetic procedure to obtain the first-generation (G1) CPE dendron, Arg4-DAG (14), is shown in Scheme 1. Full details of the synthetic strategies used and characterization of the final product and intermediates are provided in the ESI.

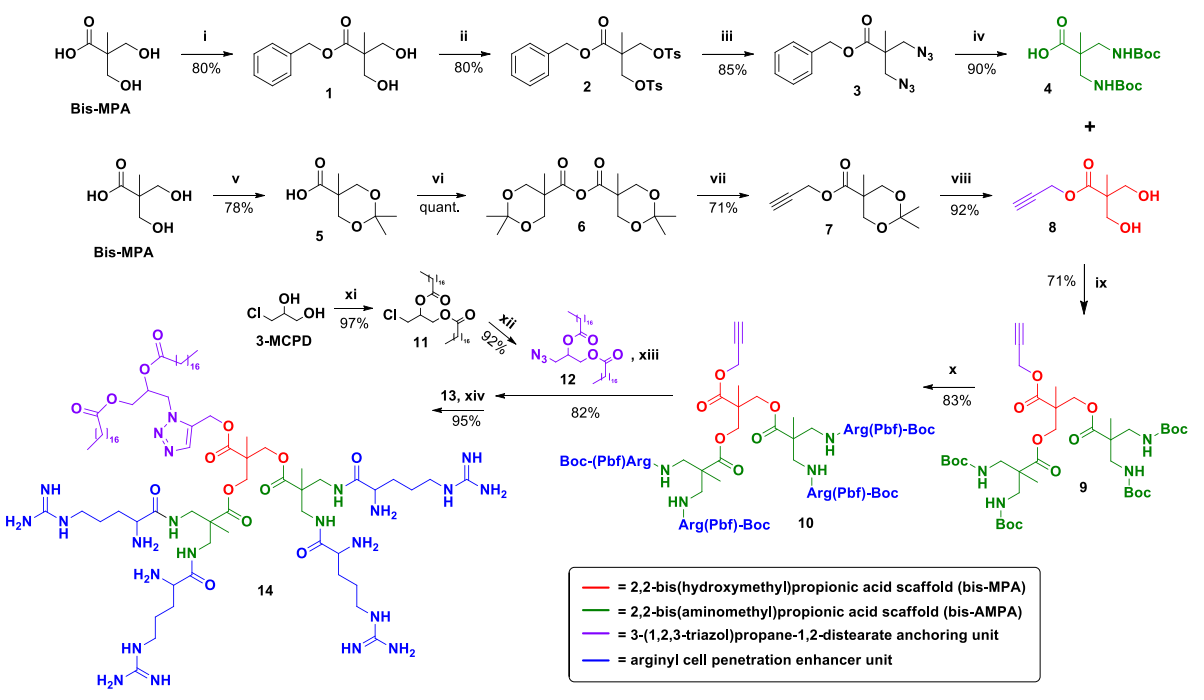

Scheme 1. Synthesis of the first-generation tetra-arginyl dendritic 3-(1,2,3-triazol)propane-1,2distearate cell penetration enhancer for the decoration of liposomes. ${ }^{a}$ 
${ }^{a}$ Reagents and conditions: (i) $\mathrm{BnBr}, \mathrm{KOH}, \mathrm{DMF}, 100^{\circ} \mathrm{C}, 15 \mathrm{~h}$; (ii) TsCl, $\mathrm{Py}, \mathrm{DMAP}, \mathrm{CH}_{2} \mathrm{Cl}_{2}, 60{ }^{\circ} \mathrm{C}, 4 \mathrm{~h}$; (iii) $\mathrm{NaN}_{3}$, DMF, $90^{\circ} \mathrm{C}, 16$ h; (iv) 1) $\mathrm{PtO}_{2}, \mathrm{H}_{2}$, (Boc) $)_{2} \mathrm{O}, \mathrm{MeOH}$, rt, 4 h; 2) 10\% $\mathrm{Pd} / \mathrm{C}, \mathrm{H}_{2}, \mathrm{MeOH}, \mathrm{rt}, 3 \mathrm{~h}$ (v) DMP, PTSA, Acetone, rt, 2 h; (vi) DCC, $\mathrm{CH}_{2} \mathrm{Cl}_{2}$, rt, 4 h; (vii) 2-propyn-1-ol, Py, DMAP, $\mathrm{CH}_{2} \mathrm{Cl}_{2}$, rt, 15 h; (viii) Dowex 50W-X8 ( $\mathrm{H}^{+}$-form), MeOH, rt, 6 h; (ix) 1) 4, DCC, $\mathrm{CH}_{2} \mathrm{Cl}_{2}, \mathrm{rt}, 16$ h; 2) 8, Py, DMAP, $\mathrm{CH}_{2} \mathrm{Cl}_{2}, \mathrm{rt}, 16 \mathrm{~h}$; (x) 1) $\mathrm{CH}_{2} \mathrm{Cl}_{2} / \mathrm{TFA}$ (1:1), rt, 2.5 h; 2) Boc-Arg(Pbf)-OH, HOBt, EDC, DIPEA, DMF, rt, 16 h; (xi) stearoyl chloride, $\mathrm{Py}, \mathrm{CH}_{2} \mathrm{Cl}_{2}, \mathrm{rt}, 16$ h; (xii) $\mathrm{NaN}_{3}$, DMF, $100{ }^{\circ} \mathrm{C}, 15 \mathrm{~h}$; (xiii) $\mathrm{CuI}$ (10 mol \%), AcOH (20 mol \%), DIPEA (20 mol \%), sodium ascorbate (10 mol \%), $\mathrm{CH}_{2} \mathrm{Cl}_{2}$, rt, 24 h; (xiv) 1) $\mathrm{CH}_{2} \mathrm{Cl}_{2} / \mathrm{TFA}(2.5: 1)$, rt, 24 h; 2) $\mathrm{CH}_{3} \mathrm{CN} / \mathrm{H}_{2} \mathrm{O}+0.05 \%$ TFA (1:1), Amberlite IRA-900 (Cl-form).

Briefly, compound (14) was synthesized by the $\mathrm{Cu}(\mathrm{I})$-catalyzed Huisgen 1,3-dipolar cycloaddition ("click" reaction) between the azide terminated distearoyl propane anchoring unit (12) and the alkynic dendron (10) to give the Pbf-Boc-protected precursor (13), followed by TFA mediated deprotection of the Arg units (xiii and xiv, Scheme 1). The 3-azidopropane-1,2distearate (12) was prepared by a two-step high yield procedure from commercially available ( \pm )-3-chloro-1,2-propanediol (3-MCPD): acylation with stearoyl chloride followed by nucleophilic substitution of chloride with azide (xi and xii, Scheme 1). The synthesis of the four branched alkynic tetra-Boc-arginyl(Pbf) scaffold (10) was achieved via anhydride coupling between 2,2-(bis((tert-butoxycarbonyl)amino)methyl)-propanoic acid (4) and propargyl 2,2bis(hydroxymethyl)propanoate (8) to yield (9) (ix, Scheme 1), followed by TFA mediated Boc deprotection and coupling with Boc- $\operatorname{Arg}(\mathrm{Pbf})-\mathrm{OH}$ (x, Scheme 1). Compound (8) was synthesized according the procedure reported by Barnard et al. with only slight modifications ${ }^{21}$ ( $\mathbf{v}-$ viii, Scheme 1). Compound (4) was synthesized by benzylation of the carboxylic function of bisMPA followed by tosylation of the two free hydroxyl groups and nucleophilic substitution of the tosylate with azide to obtain $(\mathbf{3})$ which was then reduced in a one-pot hydrogenation procedure 
involving two sequential steps: the first in the presence of $\mathrm{PtO}_{2}$ and Boc-anhydride to obtain the corresponding Boc-protected diamine and the second in the presence of $\mathrm{Pd} / \mathrm{C}$ to cleave the benzyl protecting group and obtain the desired intermediate (4) (i - iv, Scheme 1).

\subsection{Synthesis and characterization of the pH-sensitive copolymer mPEG-(poly- methacryloyl sulfadimethoxine) (mPEG (mba $\left.-\mathrm{SDM}_{8}\right)$}

mPEG-polySDM (17) was synthetized in a two-step procedure, according to a modified strategy reported in the literature. ${ }^{22}$ The activated $\left.\mathrm{mPEG}_{5} \mathrm{kDa}-\mathrm{NH}-\mathrm{CO}-\mathrm{C}-\left(\mathrm{CH}_{3}\right)_{2}\right)-\mathrm{Br}(\mathbf{1 6})$ was obtained by a-bromoisobutyryl bromide reaction with $\mathrm{mPEG}_{5 \mathrm{kDa}}-\mathrm{NH}_{2}$ (yield 90\%). The TNBS spectrophotometric analysis confirmed the complete functionalisation of the amino groups of $\mathrm{mPEG}_{5 \mathrm{kDa}}-\mathrm{NH}_{2}$ with $\alpha$-bromoisobutyryl bromide. The integrals of the ${ }^{1} \mathrm{H}$ NMR signals ( $\delta 3.65$ for the oxyethylene monomers of PEG and $\delta 1.9$ for the two methyl groups of the $\alpha$ bromoisobutyryl amide) were in agreement with a 1:1 PEG/ $\alpha$-bromoisobutyryl amide molar ratio of the AGET-ATRP initiator. The synthesis of mPEG-polySDM (17) was performed by AGETATRP polymerization of methacryloyl sulfadimethoxine (SDM, (15)) using a 1:12 $\mathrm{mPEG}_{5} \mathrm{kDa}^{-}$ $\left.\mathrm{NH}-\mathrm{CO}-\mathrm{C}-\left(\mathrm{CH}_{3}\right)_{2}\right)-\mathrm{Br} / \mathrm{SDM}$ molar ratio. The polymer was isolated with a $67 \%$ yield. The ${ }^{1} \mathrm{H}$ NMR integrals (Figure S1 in ESI) of the signals at $6.0 \mathrm{ppm}$ and $3.5 \mathrm{ppm}$, corresponding to the pyrimidyl hydrogen of SDM and the PEG oxyethylene monomers, respectively, showed that the co-polymer included, on average, 8 methacryloyl sulfadimethoxine monomers which was confirmed by UV-Vis spectroscopic analysis and iodine assay. 


\subsection{Liposome preparation}

Liposomes were prepared according to the "thin layer rehydration technique" method, ${ }^{23}$ using a 2:1 mol/mol hydrogenated soy phosphatidylcholine/cholesterol mixture. Briefly, $10 \mathrm{mg}$ of the lipid mixture was dissolved in $1.5 \mathrm{~mL}$ of $\mathrm{CH}_{2} \mathrm{Cl}_{2}$ and the organic solvent was removed under reduced pressure by rotavapor to form a lipid film and then overnight to remove any $\mathrm{CH}_{2} \mathrm{Cl}_{2}$ trace. The lipid film was rehydrated with $200 \mu \mathrm{L}$ of buffer $(0.01 \mathrm{M}$ phosphate, $0.15 \mathrm{M} \mathrm{NaCl}$ at pH 7.4 or 0.01 M HEPES, $0.15 \mathrm{M} \mathrm{NaCl}$ at $\mathrm{pH} 7.4$ and processed with ten freeze-thawing cycles.

CPE-decorated liposomes were prepared by adding $0.5 \mathrm{~mL}$ liposome dispersions $(10 \mathrm{mg} / \mathrm{mL}$ lipid concentration) of increasing volumes of a $5 \mathrm{mg} / \mathrm{mL} \mathrm{Arg}_{4}-\mathrm{DAG}$ solution in the same buffer of the liposome dispersion in order to yield $\mathrm{Arg}_{4}-\mathrm{DAG}$ in the range of $1-8 \mathrm{~mol} \%$ with respect to lipids. The liposomes were sonicated for $60 \mathrm{sec}$ with a Ultrasonic Homogenizer (Omni International, Kennesaw, GA-USA) set at 20\% power. Non-associated CPE was removed by liposome centrifugation for $30 \mathrm{~min}$ at $11,000 \mathrm{rpm}$. The liposomes were redispersed with the same buffer to a lipid concentration of $5 \mathrm{mg} / \mathrm{mL}$ and extruded eleven times at $60{ }^{\circ} \mathrm{C}$ through a $200-\mathrm{nm}$ cut-off polycarbonate membrane. The formulations were then incubated at $37^{\circ} \mathrm{C}$ for 1 hour and the $\mathrm{Arg}_{4}-\mathrm{DAG}$ content was assessed by Sakaguchi assay as reported in the ESI.

Liposomes decorated with $4 \mathrm{~mol} \%$ of $\mathrm{Arg}_{4}-\mathrm{DAG}$ with respect to lipids were incubated with increasing amounts of $\mathrm{mPEG}_{5 \mathrm{kDa}}-\mathrm{SDM}_{8}\left(0-4 \mathrm{~mol}_{0} \mathrm{mPEG}_{5 \mathrm{kDa}}-\mathrm{SDM}_{8} /\right.$ lipids molar ratio $)$ in the same buffer to obtain PEG coated pH-sensitive formulations and diluted 50 times either with 0.01 M HEPES, 0.15 M NaCl at $\mathrm{pH} 7.4$ and 7.0, or with $0.01 \mathrm{mM} \mathrm{MES,} 0.15 \mathrm{M} \mathrm{NaCl}$ at $\mathrm{pH} 6.5$ and 6.0 and the zeta potential was assessed as a proxy for the $\operatorname{Arg}_{4}-\mathrm{DAG}$ shielding and unshielding, respectively. 
Liposomes decorated with $4 \mathrm{~mol} \%$ of $\mathrm{mPEG}_{5 \mathrm{ka}-\mathrm{DSPE}}$ with respect to lipids were prepared as control with non-pH releasable PEG using a $5 \mathrm{mg} / \mathrm{mL}$ stock solution of $\mathrm{mPEG}_{5 \mathrm{ka}}-\mathrm{DSPE}$ in the same buffers.

Stability of liposomes over time was assessed at predefined time points by size and zeta potential analysis.

Fluorescent liposomes were prepared by including $0.2 \mathrm{~mol} \%$ Rhodamine-DHPE with respect to lipids in the lipid film.

\subsection{Particle size and zeta potential measurements}

Size and polydispersity, and zeta potential of liposomes were assessed by Dynamic Light Scattering (DLS) using a NanoZS Zetasizer (Malvern, Workcestershire, UK). The analyses were performed by using liposome dispersions obtained by dilution as reported above in different buffers: $0.01 \mathrm{M}$ phosphate, $0.15 \mathrm{M} \mathrm{NaCl}$ (PBS) at $\mathrm{pH} 7.4$ and $6.5 ; 0.01 \mathrm{M}$ phosphate containing $300 \mathrm{mM}$ mannitol (PBS/mannitol) at pH 7.4 and 6.5; 0.01 M HEPES, $0.15 \mathrm{M} \mathrm{NaCl}$ (HEPES) at $\mathrm{pH} 7.4 ; 0.01 \mathrm{M}$ HEPES containing $300 \mathrm{mM}$ mannitol (HEPES/mannitol) at $\mathrm{pH} 7.4 ; 0.01 \mathrm{M}$ MES, $0.15 \mathrm{M} \mathrm{NaCl}$ (MES) at $\mathrm{pH} 6.5 ; 0.01 \mathrm{M}$ MES containing $300 \mathrm{mM}$ mannitol (MES/mannitol) at $\mathrm{pH}$ 6.5. The liposome size was expressed as z-average.

Zeta potential analyses were performed using liposomes decorated with $4 \mathrm{~mol} \%$ of $\operatorname{Arg}_{4}$-DAG and coated with increasing of $\mathrm{mPEG}_{5 \mathrm{kDa}}-\mathrm{SDM}_{8} /$ lipids molar ratio in HEPES at $\mathrm{pH} 7.4$ and MES at 6.5 . 


\subsection{SAXS Analysis}

The internal structure of liposomes was analyzed by synchrotron small-angle X-ray scattering (SAXS) using an ID02 high-brilliance beamline (ESRF, Grenoble, France), with a beam cross section $200 \times 400 \mu \mathrm{m}$ and wavelength $\lambda=0.1 \mathrm{~nm}$, investigated momentum transfer region, $\mathrm{q}=$ $(4 \pi / \lambda) \sin (\theta), 0.0116<\mathrm{q}<40 \mathrm{~nm}-1,2 \theta$ scattering angle. ${ }^{24-25}$ The corresponding real-space length-scale was from 100 to $0.1 \mathrm{~nm}$. Liposome (10 mg/mL lipid concentration), CPE (5 mg/mL) and $\mathrm{mPEG}_{5 \mathrm{kDa}}-\mathrm{SDM}_{8}(5 \mathrm{mg} / \mathrm{mL})$ solutions in HEPES at $\mathrm{pH} 7.4$ and MES at 6.5 were transferred in plastic capillaries (KI-BEAM; ENKI srl, Concesio, Italy), $2 \mathrm{~mm}$ internal diameter. Measurements were performed at $25^{\circ} \mathrm{C}$ and the data were treated for angular regrouping and background subtraction, and then reported as scattered radiation intensity as a function of the momentum transfer q.

\subsection{MP-SPR measurements}

Surface plasmon resonance measurements were performed with a multi-parametric MP-SPR NaviтM 200 (BioNavis Ltd., Tampere, Finland) instrument. The system was equipped with two temperature controlled independent flow channels, inlet and outlet (waste) tubings, and a manual sample injector for both flow channels. The SPR measurements were performed with a laser wavelength of $670 \mathrm{~nm}$. The sensor chip temperature was set to $20^{\circ} \mathrm{C}$. CPE-decorated liposomes were captured and immobilized on SPR sensors consisting of a thin 6-kD carboxymethyl dextran hydrogel layer functionalized with dodecyl lipid anchors. ${ }^{26}$ The $\mathrm{pH}$-sensitive polymer $\left(\mathrm{mPEG}_{5 \mathrm{kDa}}-\mathrm{SDM}_{8}\right)$ was dissolved in running buffers (HEPES, $\mathrm{pH} 7.4$, and MES, $\mathrm{pH}$ 6.5) to 
assess polymer/liposome association under different $\mathrm{pH}$ conditions. The flow rates used for immobilizing the CPE-decorated liposomes and for monitoring the interactions between the $\mathrm{pH}$ sensitive polymer (mPEG $\left.5 \mathrm{kDa}-\mathrm{SDM}_{8}\right)$ and immobilized liposomes were 50 and $100 \mu \mathrm{L} / \mathrm{min}$, respectively.

The SPR sensors were used repeatedly after rejuvenation with an injection series of Hellmanex II $2 \%$ or CHAPS $20 \mathrm{mM}$, ethanol $80 \%$ and Milli-Q water. In between measurements, the sensors were stored immersed in CHAPS at $4{ }^{\circ} \mathrm{C}$. During the SPR measurements, the functionalized gold sensor slides were first subjected to the running buffer for the respective liposomes for approximately 5-10 min until a stable baseline was achieved. In the second phase, the liposomes were injected into both flow channels for $25 \mathrm{~min}$, and lastly, the sensor surfaces with the immobilized liposomes were exposed to seven sequential injections of $0.4 \mu \mathrm{M}, 0.8 \mu \mathrm{M}, 1.61$ $\mu \mathrm{M}, 3.23 \mu \mathrm{M}, 6.45 \mu \mathrm{M}$ and $12.9 \mu \mathrm{M} \mathrm{pH}$-sensitive polymer (mPEG $\left.{ }_{5 \mathrm{ka}}-\mathrm{SDM}_{8}\right)$ solutions in the buffers at $\mathrm{pH} 7.4$ or 6.5 .

\subsection{Liposome loading and release study}

Liposome loading with BSA-Rhodamine (BSA-Rho) and calcein and the corresponding method of the release study are reported in the ESI. 


\subsection{Cell cultures}

HeLa cells (human cervical cancer) were grown at $37^{\circ} \mathrm{C}$ in DMEM medium supplemented with 10\% (v/v) heat-inactivated fetal bovine serum (FBS), $2 \mathrm{mM} \mathrm{L-glutamine,} 100 \mathrm{IU} / \mathrm{mL}$ penicillin, $100 \mu \mathrm{g} / \mathrm{mL}$ streptomycin and $0.25 \mu \mathrm{g} / \mathrm{mL}$ of amphotericin $\mathrm{B}$, with a $5 \% \mathrm{CO}_{2}$ atmosphere. The cells were harvested by treatment with $0.05 \%(\mathrm{w} / \mathrm{v})$ trypsin- $0.02 \%(\mathrm{w} / \mathrm{v})$ EDTA solution (SigmaAldrich, St. Louis, MO-USA), suspended in culture medium and seeded at the appropriate cell concentration.

Viability studies were performed by incubation of HeLa cells with the different liposome formulations according to the procedure reported in the ESI.

\subsection{Cytofluorimetric analysis}

HeLa cells were used to evaluate the internalization of: naked liposomes (plain liposomes); PEGylated liposomes (liposomes coated with non-pH-responsive $\mathrm{mPEG}_{5 \mathrm{kDa}}-\mathrm{DSPE}$ ); liposomes decorated with 2 or 4 mol\% of $\mathrm{Arg}_{4}-\mathrm{DAG}$; pH-responsive liposomes decorated with $4 \mathrm{~mol} \%$ $\mathrm{Arg}_{4}-\mathrm{DAG}$ and coated with $4 \mathrm{~mol} \%$ of $\mathrm{mPEG}_{5 \mathrm{kDa}}-\mathrm{SDM}_{8}$, labelled with rhodamine-DHPE, or loaded with BSA-Rho or calcein. The cells were seeded in a 6 well plate at a density of $1 \times 10^{6}$ cells/well. After 24 hours, the cells were washed twice with HEPES or MES at pH 7.4 and 6.5 respectively and incubated for 1 hour at $37^{\circ} \mathrm{C}$ with $1 \mathrm{~mL}$ of $0.1 \mathrm{mg} / \mathrm{mL}$ liposomal dispersion in DMEM supplemented with $10 \%$ of FBS buffered with 0.1 M HEPES, pH 7.4, or $0.1 \mathrm{M} \mathrm{MES,} \mathrm{pH}$ 6.5. ${ }^{27}$ The medium was removed and the cells were washed three times with fresh PBS at $\mathrm{pH} 7.4$ and treated for $2 \mathrm{~min}$ with $300 \mu \mathrm{L}$ of $500 \mu \mathrm{g} / \mathrm{mL}$ trypsin in PBS without calcium and 
magnesium. DMEM (1 mL) supplemented with 10\% FBS was added to the wells to quench trypsin and the cells were recovered and centrifuged at 1,000 rpm for 5 minutes. The cellular pellet was resuspended in PBS, pH 7.4, washed twice with the same buffer and recovered by centrifugation at 1,000 rpm for 5 minutes. The cell samples were resuspended in $300 \mu \mathrm{L}$ of PBS pH 7.4, and analysed by flow cytometry using a BD FACScanto II flow cytometer (Biosciences, San Jose, Canada) equipped with a FACSDIVA software package. The cell populations were gated using forward versus side scatter to exclude debris and dead cells.

The same protocol was also used with PNT2 cells used as non-cancer cell model.

\subsection{Confocal microscopy}

The liposome association to cancer cells and cell uptake were studied by confocal microscopic imaging.

HeLa cells were seeded onto 4 -chamber tissue culture microscope slides at a $1 \times 10^{5}$ cells/chamber density. After 24 hours ( $90 \%$ confluence), the cells were washed twice with HEPES at $\mathrm{pH} 7.4$ or MES at $\mathrm{pH} 6.5$, and the medium replaced with $0.5 \mathrm{~mL}$ of $0.1 \mathrm{mg} / \mathrm{mL}$ liposome dispersions in DMEM supplemented with 10\% of FBS buffered with 0.1 M HEPES, pH 7.4, or 0.1 M MES, pH 6.5:27 Rhodamine-DHPE labelled naked liposomes (plain liposomes), liposomes coated with non-pH-responsive PEEG $_{5 \mathrm{kDa}}-\mathrm{DSPE}$ (PEG/liposomes), liposomes decorated with $4 \mathrm{~mol} \% \mathrm{Arg}_{4}-\mathrm{DAG}$ (CPE/liposomes), liposomes decorated with 4 mol\% $\mathrm{Arg}_{4}-\mathrm{DAG}$ and coated with 4 mol\% $\mathrm{mPEG}_{5 \mathrm{kDa}}-\mathrm{SDM}_{8}$ liposomes (CPE/pH-sensitive

polymer / liposomes). Liposomes loaded with BSA-Rho or calcein were also tested. After 
incubation for 1 hour at $37^{\circ} \mathrm{C}$, the medium was removed and the cells were gently washed three times with PBS, pH 7.4, and finally fixed by treatment with 4\% paraformaldehyde in PBS, $\mathrm{pH}$ 7.4, for $10 \mathrm{~min}$ in an ice bath. The cell membranes were stained by cell incubation with $5 \mu \mathrm{g} / \mathrm{mL}$ Alexa Fluor ${ }^{\circledR} 633$ conjugated wheat-germ agglutinin (WGA-AlexaFluor 633) in PBS, pH 7.4, for 10 minutes at room temperature. The cells were then washed with PBS, pH 7.4, and the samples were covered with a glass slide using Vectashield $₫$ as mounting medium containing 1.5 $\mu \mathrm{g} / \mathrm{mL}$ DAPI for nucleus staining. The samples were maintained at $4{ }^{\circ} \mathrm{C}$ in the dark until microscopic examination.

The samples were imaged by confocal laser microscopy using a LSM 800 microscope (Carl Zeiss, Jena, Germany) equipped with a 63x, n.a. 1.4, oil immersion objective and a ZEN 2.1 blue edition - software (Carl Zeiss, Jena, Germany). Lasers with emission wavelength at 405, 488, 561 and $640 \mathrm{~nm}$ were used to detect DAPI, calcein, Rhodamine-DHPE and WGA-Alexa Fluor 633, respectively. To avoid emission crosstalk, each emission fluorescence was recorded independently with specific detector and optical cut-off filter over the entire emission spectrum of related chromophores. Image analyses were performed using ImageJ $1.47 \mathrm{v}$ (National Institutes of Health software package).

\subsection{Statistical analysis}

Statistical analyses were performed with XLSTAT software (New York, USA). Two-way analysis of variance was used to calculate the threshold of significance. Statistical significance was set at $\mathrm{p}<0.05$. 


\section{RESULTS AND DISCUSSION}

The work presented here was aimed at developing a new novel strategy that provides for controlled cell up-take of nanocarriers by exploiting environmentally triggerable cell penetration enhancers (CPEs) and reversible stealthing polymers. The nanocarrier has been designed as an alternative to systems that exploit conventional "active targeting" based on cell biorecognition. Indeed, this nanocarrier can provide for intracellular drug delivery after local microenvironmental activation.

Although many efforts have been done to exploit CPEs, namely TAT derived peptides, to ameliorate the therapeutic performance of drug nanocarriers, non-specificity and lack of selective targeting strongly limits their use for fabrication of smart nanomedicines. ${ }^{28-30}$ Therefore, $\mathrm{CPE}$ exposure control by environmental stimuli is required to generate drug nanovehicles for site-selective cell targeting.

Nanocarrier stealthiness is a requisite to prevent their clearance by RES. On the other hand, stealthiness may reduce the interaction of colloidal drug carriers with the target cancer cells, which may result in poor access to the cytosol, low intracellular drug delivery and, eventually, reduced therapeutic performance.

Thus, we synthesised a new non-peptide, non-linear CPE and a pH-sensitive stealthing blockcopolymer, which were synergistically combined to produce "smart" liposomes that undergo a four-stage targeting process: 1 . circulate in the bloodstream in a dormant conformation; 2 . passively dispose in the tumor according to the enhanced permeability and retention (EPR) 
mechanism; ${ }^{31-32} 3$. are activated by microenvironmentally controlledCPE exposure; 4 . are takenup by the cells.

\subsection{Dendron cell penetration enhancer (CPE) design, synthesis and characterization.}

The novel CPE formed by multiple Arg units to the tips of a first-generation dendritic structure was designed in order to develop a molecule with enhanced physicochemical and biological features compared to synthetic and natural TAT-like peptides (CPPs), namely high stability towards proteases, lack of bioactivity and high biocompatibility. Furthermore, Sheldon reported that cell penetrating peptides with dendritic architecture typically outperform their linear monomeric homologues in term of cellular uptake. ${ }^{33-34}$

Multiple Arg units were conjugated to a first-generation dendritic structure based on a bis(aminomethyl)propionic acid (bis-AMPA) branched scaffold anchored to a core of 2,2bis(hydroxymethyl)propionic acid (bis-MPA). This dendritic architecture was selected for the excellent biocompatibility, stability under physiological conditions and biodegradability of the bis-MPA core ${ }^{35}$, which makes it suitable for clinical applications. Arg was coupled to the dendron through stable amidic bonds. Wender demonstrated that the chirality of the amino acids of TAT has a negligible effect on the cellular uptake of this class of molecules. ${ }^{36}$ Therefore, the stereochemistry of the resulting Arg-decorated dendron was not an issue in this work.

The divergent synthesis of the bis-MPA/bis-AMPA based dendron yielded multiple-arm derivatives classified as generation $(\mathrm{G})$ that corresponds to the consecutive branching points each of them end-terminating with four amino groups for Arg coupling. Notably, TAT possesses 6 
Arg (sequence: GRKKRRQRRRPQ). Therefore, the G1 and G2 bis-MPA based dendrons, which bear 4 and 8 Arg, respectively, have the closest number of Arg to the natural TAT.

The charge density of CPPs has been shown to play a key role in the cell glycocalyx crosslinking and cell penetration. Accordingly, we investigated the charge density of the G1 and G2 Arg-decorated dendrons as predicted from the average mutual distance of Arg using the Molecular Operating Environment (MOE) software (Chart 1). ${ }^{14}$

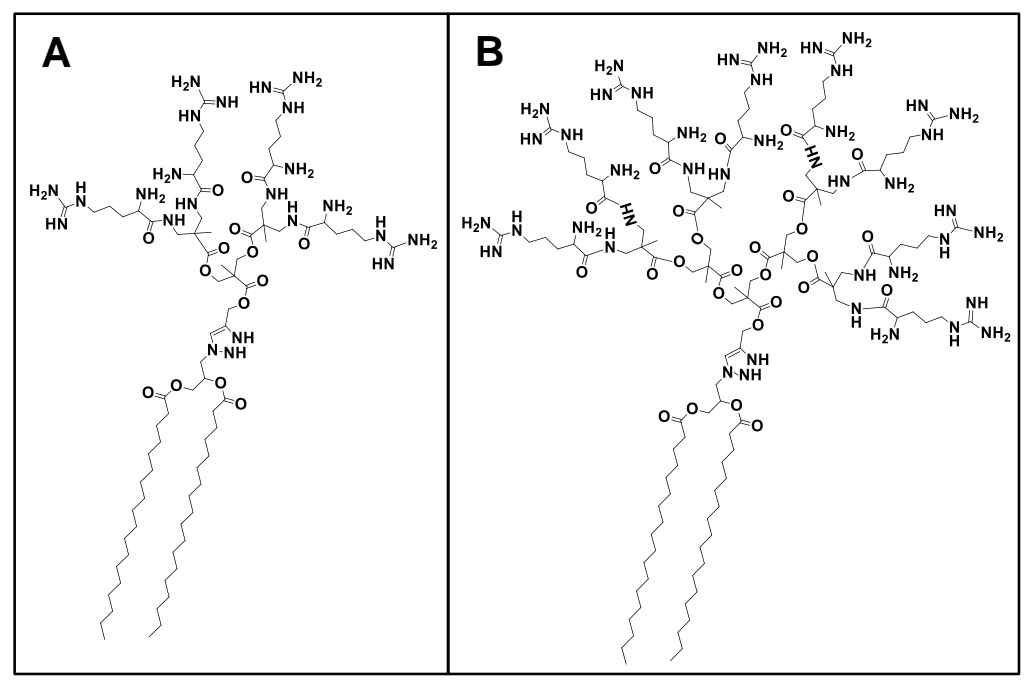

Chart 1. Structures of first generation (G1) dendron $\operatorname{Arg}_{4}-\mathrm{DAG}(\mathbf{A})$ and second generation (G2) dendron $\operatorname{Arg}_{8}-\mathrm{DAG}(\mathbf{B})$.

The in silico simulation showed that the carbon atoms of adjacent guanidinium Arg residues are separated by $10.3 \AA$ and $13.8 \AA$ in G1 (4 Arg) and G2 (8 Arg) dendrons, respectively. This result suggests that G1 dendron has higher charge density than G2 dendron. It is worth to note that You-Rim et al. investigated the correlation between the number of Arg and the cell penetration 
performance of short peptides in nanocapsular systems, showing that carriers functionalized with short peptides with only three Arg are efficiently taken-up by the cells. This was ascribed to the cooperative effect that oligo-Arg on the nanocarrier surface. ${ }^{37}$

The dendron design included the end-functionalization with a diacyl glycerol unit, 3-(1,2,3triazol)propane-1,2-distearate (DAG), to yield its association with the liposomal membrane. Considering that the resulting [hydrophobic alkyl chains]/[polycationic dendritic block] mass ratio was $1: 2.8$ and 1:4.6 for the G1 derivative (4 Arg) and the G2 derivative ( $8 \mathrm{Arg}$ ), respectively, the former, that contains a heavier anchoring fraction with respect to the latter, was expected to more stably associate with the lipid bilayer of the liposome membrane. Therefore, taking into account the higher positive charge density and the lighter cationic block, the G1 dendron bearing four $\operatorname{Arg}\left(\operatorname{Arg}_{4}-\mathrm{DAG}\right)$ was selected.

The synthetic procedure set-up for the production of $\mathrm{Arg}_{4}-\mathrm{DAG}$ provided for high structural control and monodispersity of the branched derivative, and high functional group density at the terminal ends (namely the Arg). Feliu et al. ${ }^{35}$ investigated the stability, degradability and cytotoxicity of bis-MPA based dendrons under different conditions and demonstrated the excellent biocompability and potential for exploiting these scaffolds for biomedical applications.

\section{2 pH-sensitive block-copolymer synthesis and characterization}

The acid-sensitive mPEG-(poly-methacryloyl-sulfadimethoxine) (mPEG-polySDM) stealthing block co-polymer (17) was designed to yield $\mathrm{Arg}_{4}$-DAG shielding and unshielding at the surface of CPE-decorated liposomes. 
The ionizable sulfadimethoxine (SDM) block was selected to provide the coulombic interaction of the co-polymer with the polycationic CPE. Actually, by virtue of its pKa (6.1),${ }^{38} \mathrm{SDM}$ reversibly switches from anionic to uncharged state over a narrow $\mathrm{pH}$ range close to physiopathological conditions. According to the evidence that the pKa of SDM oligomers increases with the number of monomers, ${ }^{22,39}$ a block mPEG-polySDM co-polymer formed by 7 SDM monomers was synthesised. The potentiometric titration profile reported in Figure S2 (ESI) shows that this copolymer has pKa 7.1. This result is in agreement with polymers obtained with PEG derivatives and SDM reported in the literature. ${ }^{22,39-40}$ Therefore, this co-polymer is predominantly in the polyanionic form at $\mathrm{pH} 7.4$ of blood, which allows for the charge-to-charge association with the CPEs on the liposome surface, while it switches to a less charged form at $\mathrm{pH} 6.5$ of the tumor ${ }^{22}$ which translates in a weaker electrostatic interaction with the cationic liposomes resulting in detachment from their surface and CPE unmasking (see chapter 3.4).

The length of the PEG block was selected according to the literature reports showing $5 \mathrm{kDa}$ mPEG minimizes the protein opsonisation of nanocarriers and their removal by the RES system, yielding prolonged permanence in the bloodstream. ${ }^{32,41}$

\section{$3.3 \mathrm{pH}$-sensitive liposome formulation}

$\mathrm{Arg}_{4}$-DAG decorated liposomes were prepared by rehydration of a thin lipid layer ${ }^{23}$ and CPE decoration by a spontaneous micelle transfer post-insertion technique, ${ }^{42}$ which provided for the CPE exposure on the outmost layer of the lipidic vesicles and reduced the hiding of the $\operatorname{Arg}_{4-}$ DAG in the liposome core. 
Liposomes decorated with increasing $\mathrm{Arg}_{4}-\mathrm{DAG} / \mathrm{lipids}$ molar ratio (from 1 to $8 \mathrm{~mol} \%$ ) were prepared according to the protocols reported in the literature for liposomes decorated with TATlike derivatives. ${ }^{43-45}$ The $\operatorname{Arg}_{4}-\mathrm{DAG}$ association to the liposome bilayer was assessed by zeta potential analysis. In PBS, pH 7.4, the non-decorated control liposomes exhibited a zeta potential that was nearly neutral (i.e. $-1 \mathrm{mV}$ ) while the results reported in Figure $1 \mathrm{~A}$ show that the zeta potential of the liposomes increased as the $\mathrm{Arg}_{4}-\mathrm{DAG}$ concentration on the vesicle surfaces increased up to a plateau of $+24 \mathrm{mV}$ at $4 \mathrm{~mol} \% \mathrm{Arg}_{4}-\mathrm{DAG} / \mathrm{lipid}$ ratio. These results suggest that there is a limit of $\operatorname{Arg}_{4}-\mathrm{DAG}$ association with the liposome membrane that could be explained with a charge repulsion effect, being the Bjerrum length at $\sim 150 \mathrm{mM}$ ionic strength still similar to that in water, $\sim 7 \AA$. The limited $\operatorname{Arg}_{4}-\mathrm{DAG}$ association was confirmed by the Sakaguchi assay ${ }^{46}$ which showed that more than $90 \%$ of the $\mathrm{Arg}_{4}-\mathrm{DAG}$ was associated to the lipid bilayer when $\mathrm{Arg}_{4}-\mathrm{DAG} / \mathrm{lipid}$ molar ratios between 1 and $4 \mathrm{~mol} \%$ were used to assembled liposomes while the efficiency of the CPE association to the lipid bilayer decreased from $90 \%$ to $\sim 50 \%$ with $8 \% \operatorname{Arg}_{4}-\mathrm{DAG} / \mathrm{lipid}$ molar ratio. 


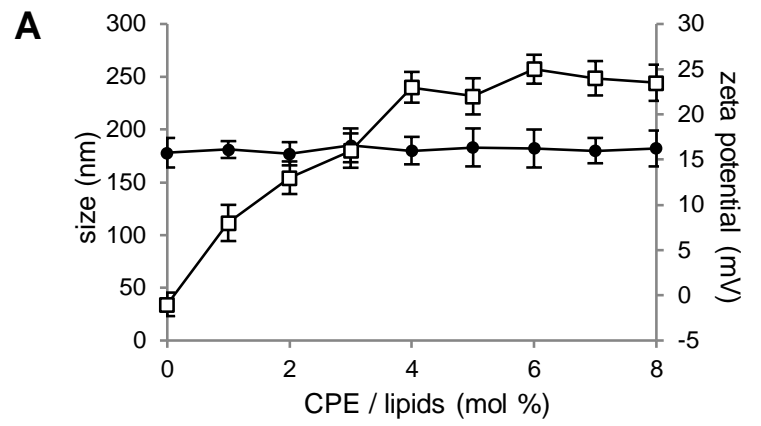

B

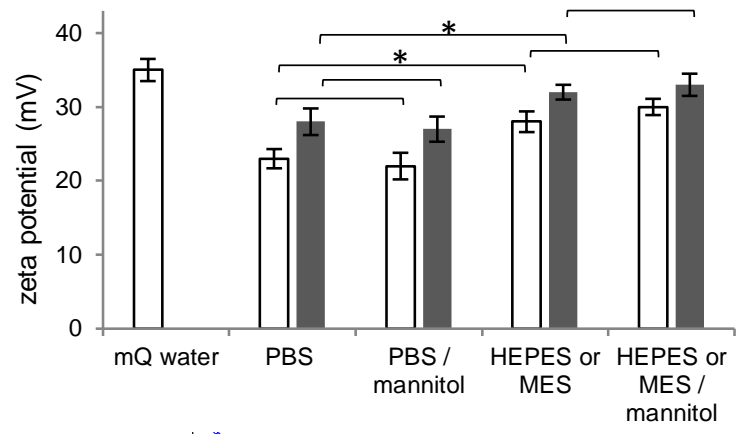

C

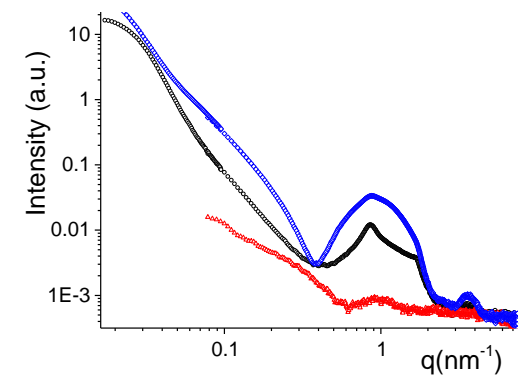

Figure 1. (A) Size $(\bullet)$ and zeta potential $(\square)$ profiles of liposomes decorated with increasing Arg 4 -DAG/lipid ratio at pH 7.4 in PBS; (B) Zeta potential of liposomes coated with 4 mol\% CPE at $\mathrm{pH} 7.4(\square)$ and $6.5(\mathbf{\square})$ in different buffers; statistical analysis: $* \mathrm{p}<0.05 ; * * \mathrm{p}<0.01$; *** $\mathrm{p}<0.001$. (C) Small angle x-ray scattering spectra of CPE alone ( $\boldsymbol{\square})$ and liposomes before ( $\mathbf{\square})$ and after $(\square)$ incubation with $\operatorname{Arg}_{4}-\mathrm{DAG} . \mathrm{T}=25^{\circ} \mathrm{C}$, HEPES buffer $\mathrm{pH}$ 7.4.

Zeta potential analyses were performed in HEPES/ $\mathrm{NaCl}$ or HEPES/mannitol at $\mathrm{pH} 7.4$ and in $\mathrm{MES} / \mathrm{NaCl}$ or $\mathrm{MES} / \mathrm{mannitol}$ at $\mathrm{pH} 6.5$ to examine the effect of $\mathrm{pH}$, buffer ionic strength and 
osmotic activity on biophysical properties of Arg 4 -DAG decorated liposomes. ${ }^{47}$ The zeta potential values determined at $\mathrm{pH} 7.4$ (mimicking the blood) were slightly lower than that at $\mathrm{pH}$ 6.5 (mimicking the tumour) regardless the buffers used for the analysis (Figure 1B). This result indicates that the overall positive charge on the liposome surface conveyed by the CPE increased as the $\mathrm{pH}$ decreased, despite the high $\mathrm{pKa}$ of the guanidinium group of $\operatorname{Arg}(\mathrm{pKa} 12.48) .{ }^{48}$ The positive charges of the $\mathrm{Arg}_{4}-\mathrm{DAG}$ decorated liposomes in phosphate (anionic buffer) at both $\mathrm{pHs}$ (7.4 and 6.5) was slightly lower than in HEPES or MES (zwitterionic buffers) indicating that the anionic species of the buffer partially quenched the Arg of $\operatorname{Arg}_{4}$-DAG. No significant differences were instead observed with different osmotic agents (mannitol and $\mathrm{NaCl}$ ). Thus, charge shielding of $\operatorname{Arg}_{4}-\mathrm{DAG}$ by buffer and osmotic agents in the aqueous medium may be related to the size of the buffer species and their overall molecular charge distribution.

Based on the zeta potential analysis, HEPES (at pH 7.4) and MES (at pH 6.5) were used as buffers for the extensive biophysical characterization of the $\mathrm{pH}$-responsive liposomes under environmental $\mathrm{pHs}$ that mimic the healthy tissue and the tumor. These two buffers are extensively used to prepare and characterize colloidal drug carriers. ${ }^{49}$

Figure 1A shows that the plain and the decorated liposomes had a vesicle size of $178 \pm 14.5 \mathrm{~nm}$ and $180 \pm 13.3 \mathrm{~nm}$, respectively, with a narrow polydispersity index (PDI 0.06), which indicates that the decoration with the synthetic CPE did not alter the formulation size. Furthermore, no size alteration was observed after 48 hours incubation at $37{ }^{\circ} \mathrm{C}$, which confirms a good colloidal stability of the vesicles as a result of the charge mediated repulsion that inhibited aggregation.

SAXS studies were performed to assess the structure of decorated liposomes. The X-ray scattering spectra reported in Figure 1C show that $\operatorname{Arg}_{4}-\mathrm{DAG}(\mathrm{CPE})$ alone formed small micelles 
(red squares in Figure 1C), which was confirmed by a fluorescence assay used to assess the critical micelle concentration $(\mathrm{CMC}=40 \mu \mathrm{M})$. The $2: 1(\mathrm{~mol} / \mathrm{mol})$

phosphatidylcholine/cholesterol liposomes before and after incubation with Arg $_{4}$-DAG (black and blue dots) showed the fingerprint of the multi-layer vesicles. Before $\mathrm{Arg}_{4}-\mathrm{DAG}$ incubation (black dots), two peaks with different intensity, at $\mathrm{q}_{1}=0.86 \mathrm{~nm}^{-1}$ and $\mathrm{q}_{2}=1.72 \mathrm{~nm}^{-1}$, were superimposed to the form factor of the individual lipid bilayer. The 1-2 periodicity of these peaks is typical of a stratified liposome, with a repetition distance $d=2 \pi / q_{1}=7.3 \mathrm{~nm}$, which is in agreement with values reported in the literature for similar 2:1 ( $\mathrm{mol} / \mathrm{mol})$

phosphatidylcholine/cholesterol layers. ${ }^{50}$ The spectrum obtained with liposomes after incubation with $\mathrm{CPE}$ at $\mathrm{pH} 7.4$ is similar to that obtained at $\mathrm{pH} 6.5$ (Figure 2C, green diamonds). Upon incubation of the liposomes with the CPE, the intensity profile dramatically changed, indicating that interaction between admixed components occurred. The final spectrum could not be obtained by simple superposition of the two, as shown in Figure S3 of the ESI. The intensity enhancement of the single-bilayer form factor and its better definition was typical for chargebearing liposomes, as compared to uncharged. Multilamellarity was still observed, with the same repetition distance, showing that CPE insertion occurred only in the external bilayer of the liposome. Then, the liposome constituted a support for the CPE that decorated its surface without deeply affecting the liposome structure.

\section{4 pH-controlled shielding of CPE decorated liposomes}

The cancer cell interaction were investigated using 4 mol\% Arg $_{4}-\mathrm{DAG}$ decorated liposomes coated with the $\mathrm{pH}$-sensitive block co-polymer $\mathrm{mPEG}_{5 \mathrm{kDa}}-\mathrm{SDM}_{8}$. 
The zeta potential analysis showed that the increase of the $[\mathrm{pH}$-sensitive polymer]/[Arg 4 -DAG] molar ratio decreased the vesicle charge due to the coulombic interaction of the polyanionic copolymer with the polycationic liposomes. The zeta potential values reported in Figure 2A show that at both $\mathrm{pH}, 7.4$ and 6.5 , the overall charge of the decorated liposomes decreased as the $\mathrm{mPEG}_{5 \mathrm{kDa}}-\mathrm{SDM}_{8} / \mathrm{Arg}_{4}-\mathrm{DAG}$ molar ratio increased. At $\mathrm{pH}$ 7.4, the $1: 1 \mathrm{mPEG}_{5 \mathrm{kDa}}-\mathrm{SDM}_{8} / \mathrm{Arg}_{4}{ }^{-}$ DAG molar ratio yielded complete liposome charge quenching, while at $\mathrm{pH} 6.5$ a residual charge $(+11 \mathrm{mV})$ was registered. This behaviour is ascribable to the $\mathrm{pH}$ dependent ionization of the polyanionic co-polymer. At pH 7.4 and 6.5, an average of 5.2 and 1.6 sulfadimethoxines (SDM), respectively, was calculated to be in the anionic form for each $\mathrm{mPEG}_{5 \mathrm{kDa}}-\mathrm{SDM}_{8}$ unit (pKa 7.1), which resulted in an unlike ability to quench the positive charges of the Arg of the CPE and thus associating with the CPE-decorated liposomes. Notably, since the $\mathrm{pH}$-sensitive liposomes at $\mathrm{pH}$ 6.5 are generated by $\mathrm{pH}$ shift from formulations at $\mathrm{pH} 7.4$, the positive zeta potential of these liposomes at $\mathrm{pH} 6.5$ supports a significant detachment of the $\mathrm{mPEG}_{5 \mathrm{kDa}}-\mathrm{SDM}_{8}$ during $\mathrm{pH}$ shifting as a consequence of the decrease of the co-polymer anionic charges (as discussed in chapter 3.2). On the contrary, the zeta potential is nearly neutral when $\mathrm{pH}$-sensitive liposomes are generated at $\mathrm{pH}$ 7.4. The residual anionic charge of the polymer at $\mathrm{pH} 6.5$ due to its apparent $\mathrm{pK}_{\mathrm{a}}$ may account for the incomplete recovery of the zeta potential of liposomes at this $\mathrm{pH}$ since a fraction of the polymer may be still associated to the vesicles surface. Indeed, the detachment of $\mathrm{mPEG}_{5 \mathrm{kDa}}-\mathrm{SDM}_{8}$ from liposome surface started at $\mathrm{pH}$ below 7 and was more remarkable as the $\mathrm{pH}$ of incubation decreased to 6.0 as a result of more extensive polymer detachment from liposomes (Figure S4).

Zeta-potential analysis of $\mathrm{Arg}_{4}-\mathrm{DAG}$ decorated liposomes incubated with 1:1 $\mathrm{mPEG}_{5 \mathrm{kDa}}{ }^{-}$ $\mathrm{OH} / \mathrm{Arg}_{4}-\mathrm{DAG}$ molar ratio showed that the ionically neutral $5 \mathrm{kDa} \mathrm{mPEG}_{5 \mathrm{kDa}}-\mathrm{OH}$ was not able 
to associate with $\mathrm{Arg}_{4}-\mathrm{DAG}$. Similarly to other anionic species present in the saline buffer, also the ionisable single SDM molecules incubated with the Arg4-DAG decorated liposomes at a 8:1 $\mathrm{SDM} / \mathrm{Arg}_{4}-\mathrm{DAG}$ molar ratio were not found to associate with the $\mathrm{Arg}_{4}-\mathrm{DAG}$ indicting that the cooperative effect of multiple anionic charges of the oligo-ionic $\mathrm{mPEG}_{5 \mathrm{kDa}}-\mathrm{SDM}_{8}$ was required to associate with the CPE. Notably, this electrostatic interaction finally resulted in the physical PEGylation of the liposomes at $\mathrm{pH} 7.4$ and charge screening.

Size analysis showed that at $\mathrm{pH} 7.4$ the $\mathrm{mPEG}_{5 \mathrm{kDa}}-\mathrm{SDM}_{8}$ coating of $\mathrm{Arg}_{4}-\mathrm{DAG}$ decorated liposomes yields a slight vesicle size increase, which supports for the association of the $\mathrm{pH}$ responsive polymer to the $\mathrm{CPE}$ decorated liposomes in agreement with data reported in the literature for post-insertion PEGylation of liposomes with 5 kDa PEG. ${ }^{51}$ The size and zeta potential analyses showed that the polymer coated vesicles were colloidally stable over 2 days while CPE-decorated liposomes (no $\mathrm{mPEG}_{5 \mathrm{kDa}}-\mathrm{SDM}_{8}$ ) showed instability after 48 hours (Figure $\mathrm{S} 5$ in ESI). 

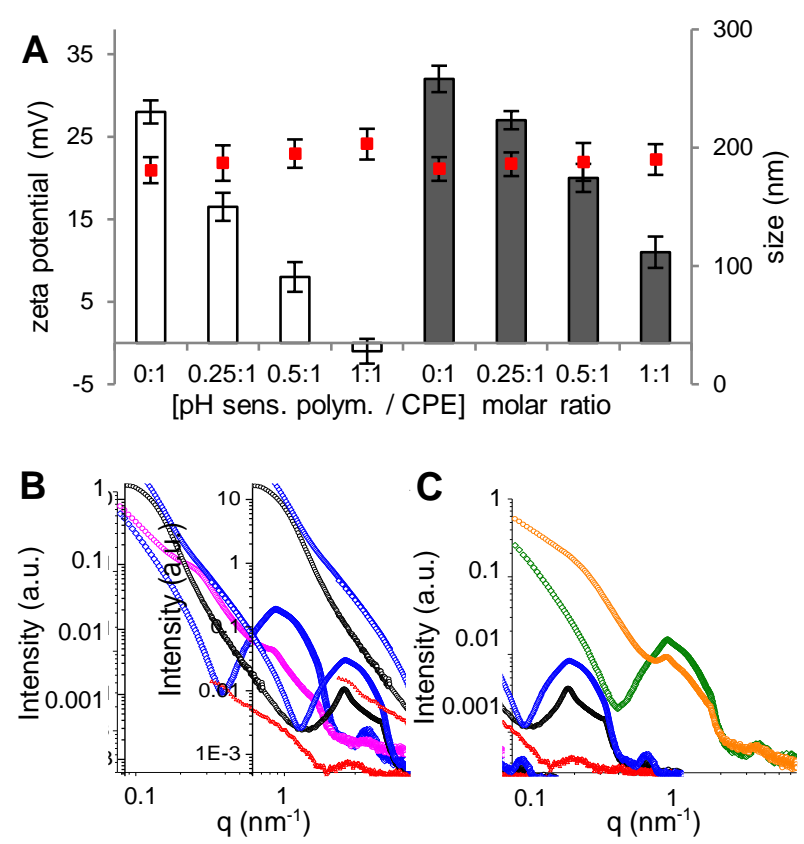

Figure 2. (A) Zeta potential (bars) and size ( $\square$ ) of Arg $_{4}-D A G$ decorated liposomes in the presence of $\mathrm{mPEG}_{5 \mathrm{kDa}}-\mathrm{SDM}_{8}$ at increasing $\mathrm{mPEG}_{5 \mathrm{kDa}}-\mathrm{SDM}_{8} / \mathrm{Arg}_{4}-\mathrm{DAG}(\mathrm{pH}$ sens. polym. / CPE) feed molar ratio, at pH $7.4(\square), 6.5$ (ם). (B) Small angle x-ray scattering spectra of $\mathrm{Arg}_{4}-\mathrm{DAG}$ decorated at $\mathrm{pH} 7.4$, before $(\diamond)$ and in the presence of $\mathrm{mPEG}_{5 \mathrm{kDa}}-\mathrm{SDM}_{8}(\diamond)$ and $(\mathbf{C})$ at $\mathrm{pH} 6.5$, before $(\diamond)$ and in the presence of $\mathrm{mPEG}_{5 \mathrm{kDa}}-\mathrm{SDM}_{8}(\diamond)$.

SAXS spectra of $\mathrm{Arg}_{4}-\mathrm{DAG}$ decorated liposomes at $\mathrm{pH} 7.4$ (B) and $\mathrm{pH} 6.5$ (C) reported in Figure 2 show that the $\mathrm{mPEG}_{5 \mathrm{kDa}}-\mathrm{SDM}_{8}$ addition modified the scattering profile of the liposomal dispersions. The internal structure was maintained for both systems, as shown by the persistence of the intensity peak at $\mathrm{q} 1=0.86 \mathrm{~nm}^{-1}$, revealing that the multi-layered liposomal core structure was preserved, with the same repeat distance, $7.3 \mathrm{~nm}$. Also, intensity oscillations in the higher q region of the spectra display similar features, indicating that the individual lamellae maintain the same thickness. However, it is evident that the scattering profile was more modified at $\mathrm{pH} 7.4$ 
(Figure 2B) than at $\mathrm{pH} 6.5$ (Figure $2 \mathrm{C}$ ) by the addition of $\mathrm{mPEG}_{5 \mathrm{kDa}}-\mathrm{SDM}_{8}$. Altogether, these results suggest that modifications were mainly related to the structure of the outer shell of the liposomes. At pH 7.4 a large association of the $\mathrm{pH}$-sensitive polymer with the external surface of decorated liposomes can be inferred, while at lower $\mathrm{pH}$ the scattering profile was consistent with the presence of free PEG in solution. An example of reconstruction of the experimental data is reported in Figure S6 of the ESI.

Surface plasmon resonance (SPR) studies were performed to further investigate the association of the $\mathrm{pH}$-sensitive polymer with CPE decorated liposomes immobilized on sensorichip (Figure S7 in ESI). ${ }^{26,52-53}$ The real-time SPR profiles to increasing additions of $\mathrm{mPEG}_{5 \mathrm{kDa}}-\mathrm{SDM}_{8}$ to $\mathrm{Arg}_{4^{-}}$ DAG liposomes reported in Figure 3A show that at $\mathrm{pH} 7.4$ the SPR response was considerably higher than at $\mathrm{pH}$ 6.5. This result confirms that $\mathrm{mPEG}_{5 \mathrm{kDa}}-\mathrm{SDM}_{8}$ interacted more efficiently at $\mathrm{pH} 7.4$ than at $\mathrm{pH} 6.5$ as a consequence of the fact that at $\mathrm{pH} 7.4$ and $\mathrm{pH} 6.5$ each $\mathrm{mPEG}_{5 \mathrm{kDa}^{-}}$ $\mathrm{SDM}_{8}$ unit possessed on average 5.2 and 1.6 SDM in the anionic state, respectively.
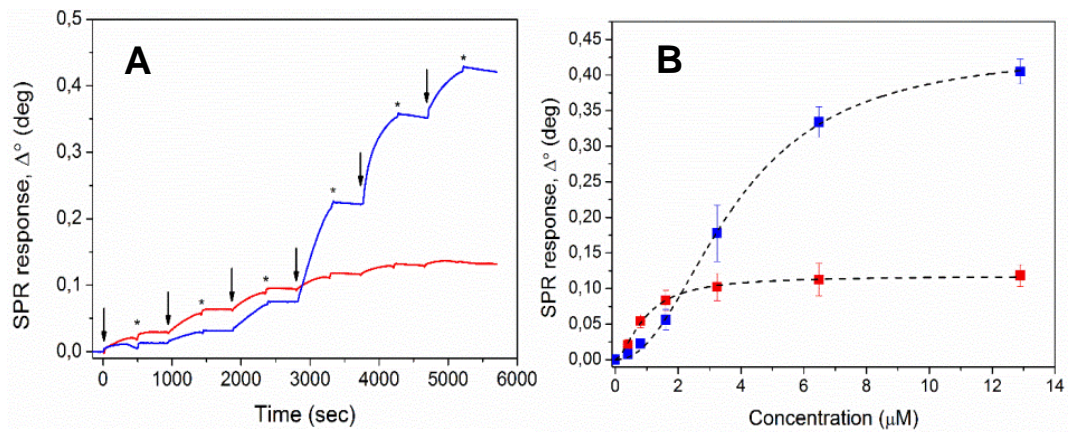

\begin{tabular}{|c|c|c|}
\hline & pH 6.5 & pH 7.4 \\
\hline $\mathbf{B}_{\max }\left(\mathbf{m}^{\circ}\right)$ & 118 & 435 \\
\hline $\boldsymbol{\alpha}$ & 1.64 & 2.17 \\
\hline$\left(\mathbf{K}_{\mathbf{c o}}\right)^{\boldsymbol{\alpha}}\left(\mathbf{M}^{-1}\right)^{\boldsymbol{\alpha}}$ & $7.75 \times 10^{9}$ & $5.74 \times 10^{11}$ \\
\hline $\mathbf{K}_{\mathbf{c o}}\left(\mathbf{M}^{-1}\right)$ & $1.07 \times 10^{6}$ & $2.63 \times 10^{5}$ \\
\hline $\mathbf{R}^{2}$ & 0.997 & 0.999 \\
\hline
\end{tabular}

Figure 3. (A) Representative MP-SPR signal responses during interaction of increasing concentrations of $\mathrm{mPEG}_{5 \mathrm{kDa}}-\mathrm{SDM}_{8}$ at $\mathrm{pH} 6.5$ (-) and 7.4 (-) through in situ PEGylation of Arg4-DAG liposomes immobilized on the SPR sensor surface. Down arrows indicate injection time points of the $\mathrm{pH}$-sensitive polymer, while stars indicate injection time points for the running 
buffer. (B) Binding isotherms at pH 6.5 ( $\square$ ) and 7.4 ( $(\mathbf{)})$ for $\mathrm{mPEG}_{5 \mathrm{kDa}}-\mathrm{SDM}_{8}$ interaction with Arg 4 -DAG decorated liposomes immobilized on the SPR sensor surface $(\mathrm{N}=3)$. Dashed black lines are fits of the co-operative binding model to the data points. Table: $\mathrm{B}_{\max }$ values, cooperativity coefficients $(\alpha)$, overall cooperative binding constant $(\mathrm{Kco})^{\alpha}$, and average cooperative binding constant $\left(\mathrm{K}_{\mathrm{co}}\right)$ at $\mathrm{pH} 6.5$ and 7.4 for $\mathrm{mPEG}_{5 \mathrm{kDa}}-\mathrm{SDM}_{8}$ interaction with $\mathrm{Arg}_{4^{-}}$ DAG liposomes immobilized on the SPR sensor surface.

Since the association of $\mathrm{mPEG}_{5 \mathrm{kDa}}-\mathrm{SDM}_{8}$ with $\mathrm{Arg}_{4}-\mathrm{DAG}$ liposomes involves multiple charge interactions, multivalent ligands and multi-subunit substrates, the binding constants and mechanism could be determined by a co-operative binding model analysis according to the following equation: ${ }^{54-55}$

$$
B=\frac{[P]^{\alpha}\left(K_{c o}\right)^{\alpha}}{1+[P]^{\alpha}\left(K_{c o}\right)^{\alpha}} .
$$

where $\mathrm{B}=\mathrm{SPR}$ signal response, $[\mathrm{P}]=$ concentration of $\mathrm{mPEG}_{5 \mathrm{kDa}}-\mathrm{SDM}_{8}, \alpha=$ co-operativity coefficient and $\mathrm{K}_{\mathrm{co}}=$ average cooperative binding constant. If the co-operativity of the binding is positive, then the first ligand facilitates the binding of the next ligand. If the co-operativity of the binding is negative, then each subsequent ligand is bound less strongly than the previous one. One-site, positive and negative co-operative binding models are obtained when the co-operativity coefficient $\alpha$ is $1, \alpha>1$ and $\alpha<1$, respectively. The binding constants $K_{1}, K_{2}, \ldots, K_{N}$ for each charged interaction will not be the same and, therefore, only average co-operative binding constants can be obtained, i.e. $\mathrm{K}_{\mathrm{co}}$ that is the average co-operative binding constant and $\mathrm{K}_{\mathrm{tot}}=$ $\left(K_{c o}\right)^{\alpha}$ that is the overall average co-operative binding constant. 
Figure 3B shows the co-operative binding isotherm of $\mathrm{mPEG}_{5 \mathrm{kDa}}-\mathrm{SDM}_{8}$ interaction with $\mathrm{Arg}_{4-}$ DAG decorated liposomes immobilized on the SPR sensor surface. The regression coefficients fitting co-operative models at $\mathrm{pH} 6.5$ and 7.4 were 0.997 and 0.999 , respectively. The $\mathrm{B}_{\max }$ value obtained at $\mathrm{pH} 7.4$ was almost 4 times higher than at $\mathrm{pH} 6.5$, which was consistent with much higher association of $\mathrm{mPEG}_{5 \mathrm{kDa}}-\mathrm{SDM}_{8}$ with the $\mathrm{Arg}_{4}-\mathrm{DAG}$ decorated liposomes at $\mathrm{pH} 7.4$ as discussed above. The co-operativity coefficients at both $\mathrm{pH}$ values are clearly larger than 1 , which suggests that the interaction of $\mathrm{mPEG}_{5 \mathrm{kDa}}-\mathrm{SDM}_{8}$ with $\mathrm{Arg}_{4}-\mathrm{DAG}$ liposomes displays a positive co-operativity at both $\mathrm{pH}$ values. The overall average binding constants $\mathrm{K}_{\mathrm{tot}}=\left(\mathrm{K}_{\mathrm{co}}\right)^{\alpha}$ had very high values and was higher at $\mathrm{pH} 7.4$ (i.e. $5.74 \times 10^{11}$ ) than at $\mathrm{pH} 6.5$ (i.e. $7.75 \times 10^{9}$ ), which once again corroborates the higher association of $\mathrm{mPEG}_{5 \mathrm{kDa}}-\mathrm{SDM}_{8}$ with $\mathrm{Arg}_{4}-\mathrm{DAG}$ liposomes at $\mathrm{pH}$ 7.4. However, the average binding constants $\left(\mathrm{K}_{\mathrm{co}}\right)$ showed a reverse trend indicating a higher value at $\mathrm{pH} 6.5$ (i.e. $1.07 \times 10^{6}$ ) compared with $\mathrm{pH} 7.4$ (i.e. $2.63 \times 10^{5}$ ). This kind of behavior is expected for systems exhibiting strong positive co-operativity as the individual binding constant increases with each bound ligand, i.e. $\mathrm{K} 1<\mathrm{K} 2<\mathrm{K} 3 \ldots$ until the saturation limit is reached, which results in that $K_{\text {tot }}>>K_{\text {co. }}$. Furthermore, the smaller the $K_{\text {co }}$ value the higher the charge ratio is required to reach the saturation level of the system, which was also reflected in the interaction of $\mathrm{mPEG}_{5 \mathrm{kDa}}-\mathrm{SDM}_{8}$ with $\mathrm{Arg}_{4}-\mathrm{DAG}$ liposomes when comparing the two different $\mathrm{pH}$ conditions.

Since liposomes are exposed to serum proteins upon parenteral administration, stability studies were performed by incubation in foetal bovine serum (FBS) at pH 7.4 and 6.5 (Figure 4). The size increase of CPE-decorated liposomes at both pHs could be ascribed to a combined effect of "protein corona" formation due to the high positive zeta potential and possible aggregation. This hypothesis is in agreement with results reported in the literature ${ }^{56-57}$ including the SPR 
measurements of protein adsorption on the oligo-arginyl decorated liposomes we reported in our previous studies. ${ }^{53} \mathrm{mPEG}_{5 \mathrm{kDa}}-\mathrm{SDM}_{8}$ coating reduced the liposome size increase at $\mathrm{pH} 7.4$ indicating that the $\mathrm{pH}$-sensitive polymer reduced the opsonization of the cationic liposomes. This result is also in agreement with our SPR outcomes reported in the literature showing that the CPE decorated liposomes coated with polyanionic-PEG display a thinner protein corona with respect to the polyanionic-PEG free formulation. ${ }^{53}$ On the other hand, at $\mathrm{pH} 6.5$ in the presence of FBS, the dissociation of the $\mathrm{mPEG}_{5 \mathrm{kDa}}-\mathrm{SDM}_{8}$ from the liposome induced a size increase of the vesicles that was comparable to that of the $\mathrm{mPEG}_{5 \mathrm{kDa}}-\mathrm{SDM}_{8}$ free $\mathrm{CPE}$-decorated liposomes confirming that, under this $\mathrm{pH}$ condition, the liposome surface was prevalently exposed to protein adsorption. ${ }^{32,58-59}$

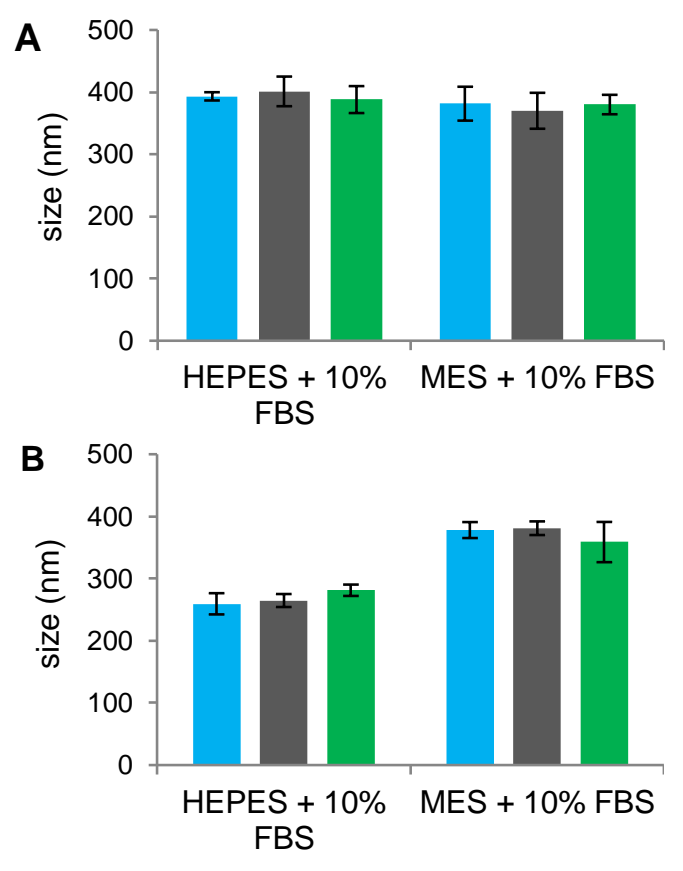

Figure 4. Size of CPE decorated liposomes (A) and CPE decorated liposomes formulated with $\mathrm{mPEG}_{5 \mathrm{kDa}}-\mathrm{SDM}_{8}$ (B) in $0.01 \mathrm{M}$ HEPES, $0.15 \mathrm{M} \mathrm{NaCl}$ at $\mathrm{pH} 7.4$ and $0.01 \mathrm{M} \mathrm{MES}, 0.15 \mathrm{M}$ $\mathrm{NaCl}$ at 6.5 after $0(\varpi), 1(\varpi), 2(\varpi)$ hours from addition of $10 \% \mathrm{FBS}$. 


\subsection{Biological Studies}

\subsubsection{Effect of CPE on liposome association to cells}

Cell association and internalization studies were carried out using naked liposomes (control) and 2 and 4 mol\% Arg 4 -DAG decorated liposomes labelled with rhodamine-DHPE.

The cytofluorimetric results reported in Figure 5A show that the cell association increased with the $\mathrm{Arg}_{4}-\mathrm{DAG}$ density on liposome surface. The decoration of liposomes with $4 \mathrm{~mol} \% \mathrm{CPE}$ (zeta potential $=+28 \mathrm{mV}$ ) increased the liposome association to cells of 31 times (referred to the MFI) with respect to naked liposomes (zeta potential $=-1 \mathrm{mV})$ and 11 times with respect to $2 \mathrm{~mol} \%$ Arg 4 -DAG decorated liposomes (zeta potential $=+13 \mathrm{mV}$ ).

Cell association of the CPE-decorated liposomes can be mediated by the protein corona adsorbed on liposome surface. ${ }^{56}$ However, despite the presence of the protein corona, interaction of the CPEs with the cell glycocalyx when liposomes approach the cell membrane may take place and mediate the association of the liposomes with HeLa cells. Further investigations are required to elucidate in details at molecular level the mechanism of cell entry mediated by this novel CPE which is a quite complex event. 

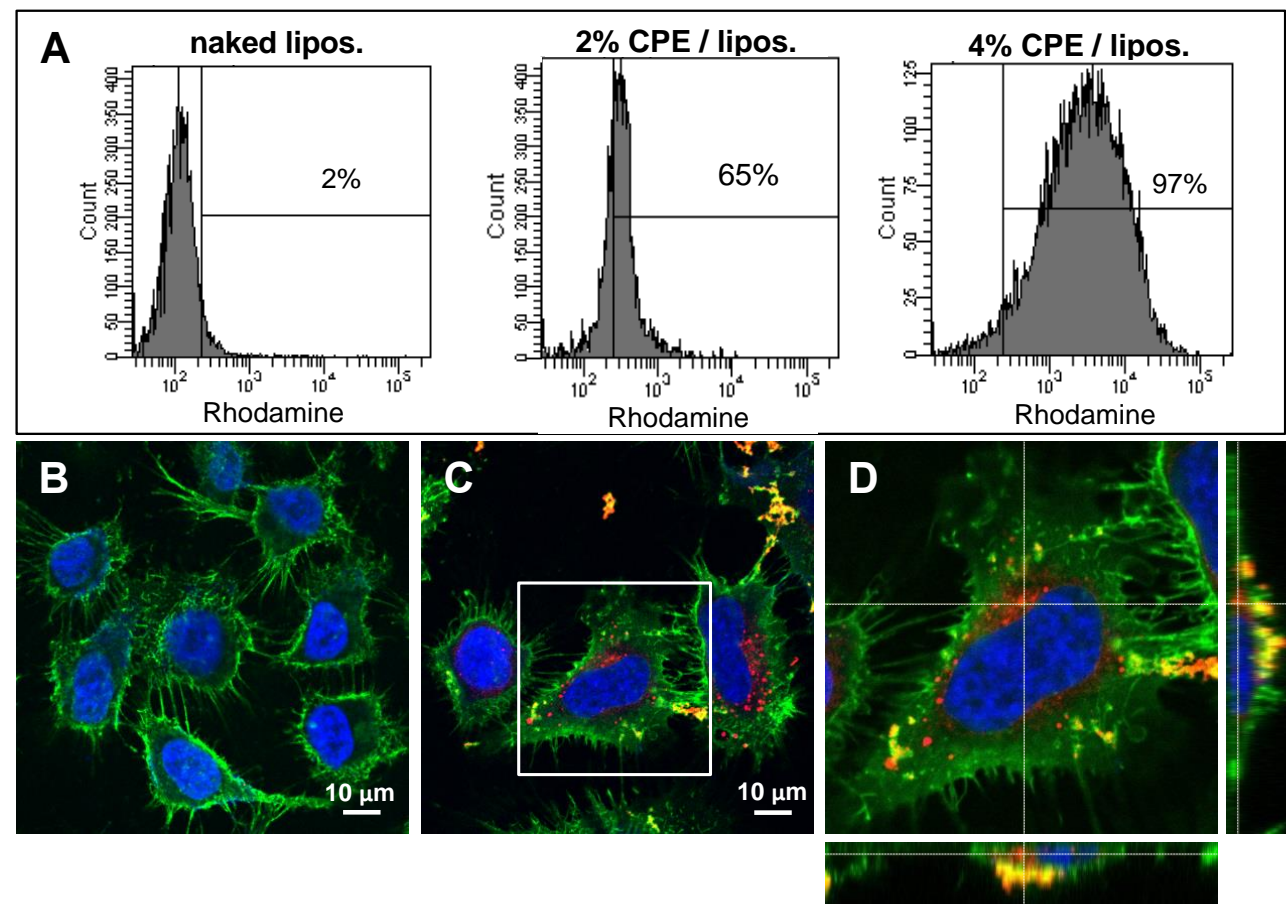

Figure 5. (A) Cytofluorimetric profile of HeLa cells incubated with naked liposomes (naked lipos.), liposomes decorated with $2 \mathrm{~mol} \%$ (2\% CPE/lipos.) and with $4 \mathrm{~mol} \%$ (4\% CPE/lipos.) of $\mathrm{Arg}_{4}-\mathrm{DAG}$ in medium at pH 7.4. (B) Confocal microscopic images of HeLa cells incubated with fluorescently labelled naked liposomes and (C) liposomes decorated with 4 mol\% of Arg -DAG $_{4}$ in medium at $\mathrm{pH}$ 7.4. (D) Magnification of the white square in (C) and Z-stack projection. Cell nuclei were stained with DAPI (blue), membranes with WGA-AlexaFluor 633(green) and liposomes were fluorescently labelled with Rhodamine-DHPE (red).

The confocal microscopic analysis confirmed that the CPE decoration remarkably enhanced the liposome association to cells and showed the vesicles accessed to the HeLa cell cytoplasm (Figure 5 B-D). The cytoplasm disposition of liposomes was confirmed by the z-stack projection (Figure 5D) from image of Figure 5C, which highlighted that the liposomes (red spots) were 
mainly located within the cytosol and disposed in proximity of the cell membrane (green) a and not in the nucleus (blue).

\subsection{2 pH-controlled association of CPE-decorated liposomes to cancer cells}

CPE-decorated liposomes (4 mol\% $\mathrm{Arg}_{4}-\mathrm{DAG} / \mathrm{lipids}$ ) coated with the $\mathrm{pH}$-sensitive co-polymer $\mathrm{mPEG}_{5 \mathrm{kDa}}-\mathrm{SDM}_{8}\left(1: 1 \mathrm{Arg}_{4}-\mathrm{DAG}_{\mathrm{mPEG}} \mathrm{kDa}_{2}-\mathrm{SDM}_{8}\right.$ molar ratio) were tested with HeLa cancer cells at pH 7.4 and 6.5, which mimic blood and extracellular tumour environments, respectively. HeLa cells were selected since they are a well-established cancer cell model. Anderson and coworkers extensively characterized the tumor generated with these cells. He showed that interstitial space of this tumor has $\mathrm{pH} 6.5 \pm 0.2 .^{60}$ Thus, we identified $\mathrm{pH} 6.5$ a representative condition to investigate association of the $\mathrm{pH}$ responsive liposomes with this model cell line. Figure $6 \mathrm{~A}$ and $\mathrm{B}$ shows that at $\mathrm{pH} 6.5$ the cells displayed a 6-fold higher mean fluorescence intensity (MFI) with respect to $\mathrm{pH}$ 7.4. Almost all cells (99\%) were fluorescently positive to liposomes at $\mathrm{pH} 6.5$ while cells were mostly spare from interaction with $\mathrm{pH}$ responsive liposomes when incubated at $\mathrm{pH}$ 7.4. Studies showed that $\mathrm{mPEG}_{5 \mathrm{kDa}}-\mathrm{SDM}_{8}$-free $\mathrm{CPE}$-decorated liposomes massively associated with the cells regardless the incubation $\mathrm{pH}$ (Figure $5 \mathrm{~A}$, and Figure S8and S9 in ESI). Furthermore, control liposomes decorated with 4 mol\% of commercial $\mathrm{mPEG}_{5 \mathrm{kDa}}-\mathrm{DSPE}$ yielded negligible cell association at both $\mathrm{pHs}$ (Figure 6A). 


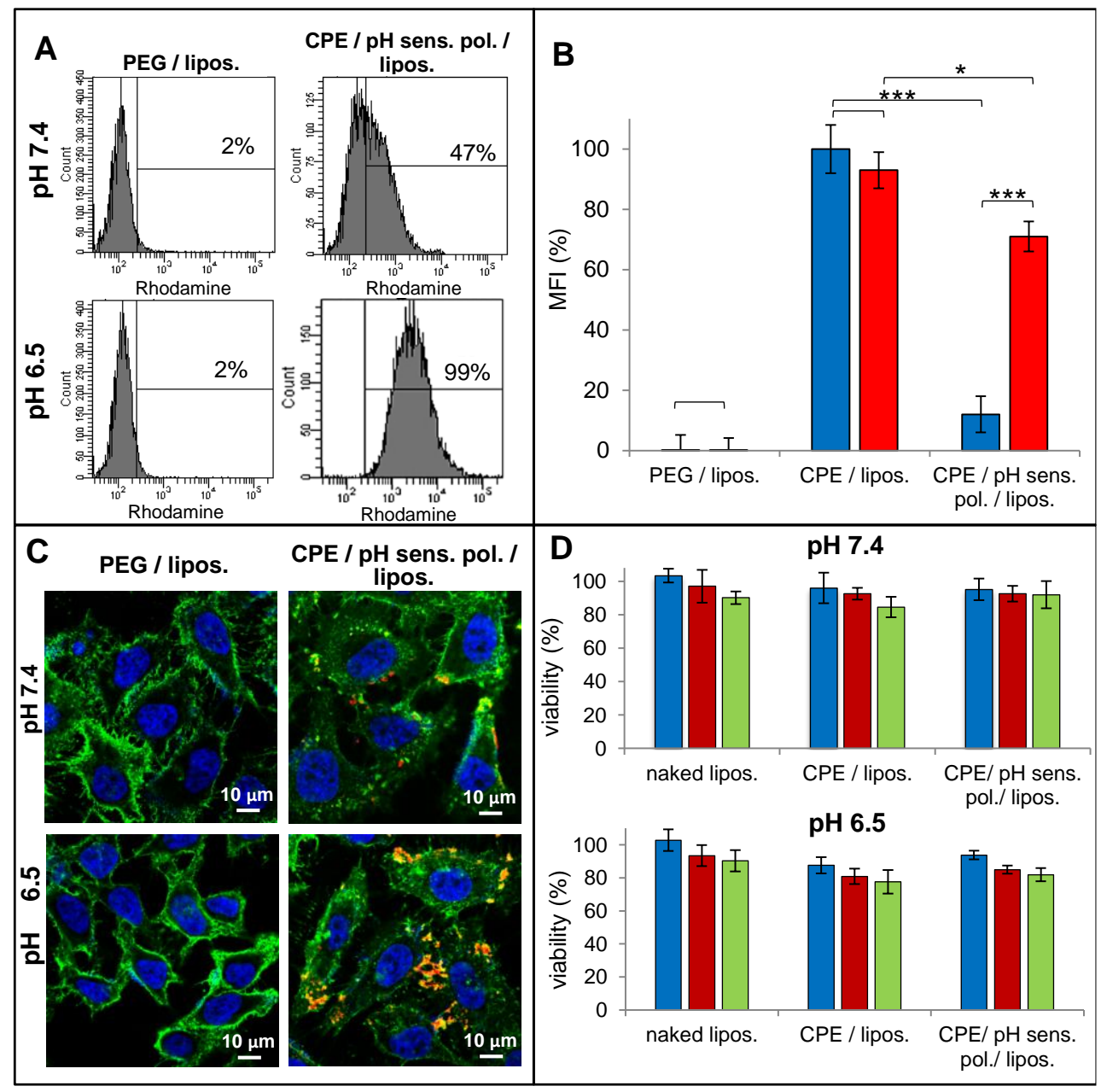

Figure 6. (A) Cytofluorimetric profile of HeLa cells incubated with rhodamine-DHPE labelled $\mathrm{mPEG}_{5 \mathrm{kDa}}$-DSPE coated liposomes, and CPE-decorated liposomes with $\mathrm{pH}$-responsive polymer in medium at $\mathrm{pH} 6.5$ and 7.4. (B): relative MFI\% of cells incubated with liposomes in medium at pH $7.4(\square)$ and $6.5(\square)$ derived from Figure (A). 100\% relative MFI was attributed to cells incubated with CPE-decorated liposomes in medium at $\mathrm{pH} 7.4$. Statistical analyses: $* \mathrm{p}<0.05$; $* *$ $\mathrm{p}<0.01 ; * * * \mathrm{p}<0.001$. (C) Confocal microscopic images of HeLa cells incubated with: $\mathrm{mPEG}_{5 \mathrm{kDa}}$-DSPE coated liposomes, and CPE-decorated liposomes with $\mathrm{pH}$-responsive polymer at pH 6.5 and 7.4. (D) Cytotoxicity profile of HeLa cells incubated with naked liposomes, CPE- 
decorated liposomes with and without $\mathrm{pH}$-responsive polymer in medium at $\mathrm{pH} 7.4$ and 6.5 at $0.1(\square), 0.5(\square)$ and $1(\square) \mathrm{mg} / \mathrm{mL}$ for 6 hours.

The confocal microscopy images reported Figure $6 \mathrm{C}$ confirmed the $\mathrm{pH}$ controlled association of the $\mathrm{mPEG}_{5 \mathrm{kDa}}-\mathrm{SDM}_{8}$ coated $\mathrm{Arg}_{4}-\mathrm{DAG}$ decorated liposomes with HeLa cells. The intense cell associated fluorescence detected at $\mathrm{pH} 6.5$ was a consequence of the dissociation of $\mathrm{mPEG}_{5 \mathrm{kDa}}{ }^{-}$ $\mathrm{SDM}_{8}$ from the $\mathrm{Arg}_{4}$-DAG units on liposome surface which restored the CPE on the liposome surface yielding their preferential association to cells under acid conditions. On the contrary, at pH 7.4 only few red fluorescent spots were detected on the outer cell surface in proximity of cell membrane.

Oppositely to several cationic liposomes that display inherent high cytotoxicity ${ }^{61}$ Figure 6D shows that the $\mathrm{Arg}_{4}$-DAG decorated liposomes possessed a negligible cell toxicity, which was similar to that of naked liposomes. Recent studies proved that cationic liposomes obtained by Arg decoration cause low cell toxicity when compared to the positive control Lipofectamine ${ }^{\mathrm{TM}}$ 2000. This result was attributed to the presence of amino acid analogs within the lipidic composition, ${ }^{62}$ which may provide a different interference of the liposomes with the membrane function and integrity of the cell or the subcellular compartments with respect to commercial lipids such as DOTAP. ${ }^{63-64}$ Notably, the presence of the $\mathrm{pH}-$-responsive polymer, both at $\mathrm{pH} 7.4$ and 6.5, did not alter the biocompatibility of the CPE-decorated liposomes.

Interestingly, a control study carried out with human epithelial PNT2 cells, at pH 7.4, showed that under physiological conditions the $\mathrm{pH}$ responsive liposomes do not significantly interact with non-cancer cells (Figure S10). On the contrary, the CPE decorated liposomes showed an 
unspecific remarkable interaction with the cells. This result further supports the environmental activation of the $\mathrm{pH}$ sensitive carrier, which can avoid interactions with normal cells under physiological conditions, namely at $\mathrm{pH}$ 7.4.

\subsubsection{Enhancement and $\mathrm{pH}$ controlled delivery of liposome payload}

Calcein and BSA loaded CPE-decorated liposomes were used to investigate the intracellular drug delivery.

Calcein was chosen as model hydrophilic molecule that does not cross lipid bilayers, thus it mimics drugs with negligible access to the intracellular compartment. ${ }^{65}$ The calcein loaded CPEdecorated vesicles displayed a size of $187 \pm 8 \mathrm{~nm}$ with a polydispersity index of 0.117 , and the loading capacity and encapsulation efficiency were found to be $52 \mu \mathrm{g}$ calcein $/ \mathrm{mg}$ lipids and $5.6 \%$, respectively.

Proteins possess low permeability across biological membranes while the intracellular delivery can have therapeutic applications for those possessing cytosolic targets. Thus, a delivery system is required to promote the access of these macromolecules to the intracellular targets. ${ }^{66}$ BSA was selected as model biomacromolecule since it was already exploited to study the delivery of proteins encapsulated in liposomes. ${ }^{67}$ Proteins with surface hydrophobic regions, such as BSA, ${ }^{68}$ may favorably associate with the lipidic components of liposomes during the loading process and thus be suitably encapsulated. Notably, a consensus exists concerning the favorable effect of the protein/lipid interaction on the protein loading efficiency in liposomes. ${ }^{69}$ Although extensive BSA labelling was considered useful to emphasize the cell up-take results, in the present study, 
BSA was labelled with a minimal amount of Rhodamine (3 Rhodamine molecules per BSA, Figure S11) in order to avoid structural protein alteration. BSA-Rho loaded CPE-decorated liposomes were obtained with a size of $201 \pm 6 \mathrm{~nm}$ and a polydispersity index of 0.197 . The slight size increase of BSA-Rho loaded liposomes with respect to their non-loaded counterparts was already observed in our previous work. ${ }^{67}$ After removal of the non-loaded BSA-Rho, RPHPLC analysis indicated a loading capacity of $25.2 \mu \mathrm{g}$ BSA-Rho/mg lipids and an encapsulation efficiency of $2.52 \%$.

The release study from CPE-decorated liposomes was carried out in buffer at pH 7.4 and pH 6.5, mimicking the blood and extracellular tumour environments, respectively (Figure 7).

Preliminary studies confirmed that calcein fluorescence is not affected by the $\mathrm{pH}$. The study showed that the encapsulated calcein is not released by liposomes at the two $\mathrm{pH}$ conditions for at least 16 days, which is consistent with the low permeability of calcein across the lipid bilayer ${ }^{65}$ and with the fact that the CPE does not alter the vesicle membrane permeability (Figure 7A).

A

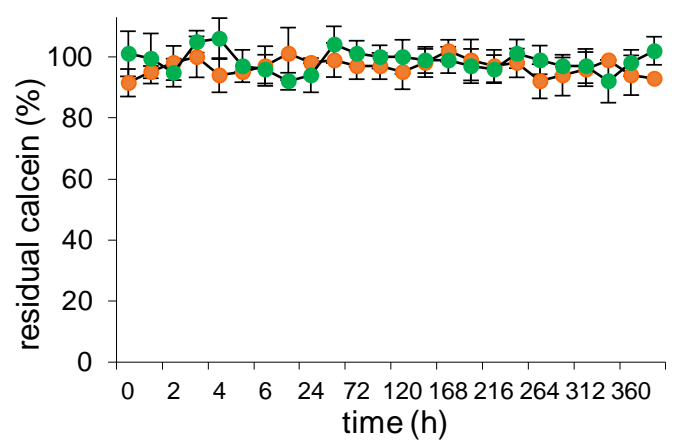

B

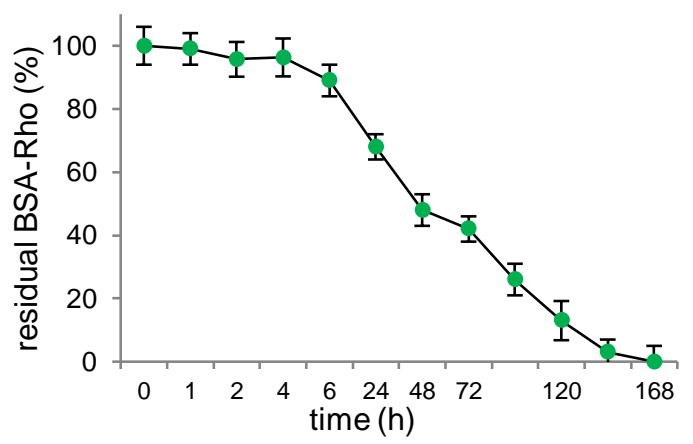

Figure 7. Calcein (A) and BSA-Rho (B) release profile from CPE-decorated liposomes in PBS at $\mathrm{pH} 7.4(\bullet)$ and $6.5(\bullet)$ at $25^{\circ} \mathrm{C}$. 
The release profiles reported in Figure 7B indicate that the release of BSA-Rho is quite slow in the first 6 hours and that approximately $30 \%$ of the loaded protein was released in $24 \mathrm{~h}$. Notably, BSA-Rho release was complete in about 7 days. The release profile was very similar to that observed for PEG decorated liposomes reported in our previous study ${ }^{67}$ To note that the decoration of liposomes with $\mathrm{CPE}$, as well as the $\mathrm{pH}$ conditions (Figure S12), neither altered the loading capacity nor the release profile of the vesicles.

The enhancement of delivery of small hydrophilic molecules to cancer cells was tested with calcein loaded CPE-decorated liposomes. The results of the flow cytometric investigation reported in Figure 8A, showed the ability of the CPE-decorated vesicles to deliver calcein to HeLa cells while the free calcein and calcein loaded naked liposomes did not associate to the cells. All cells treated with CPE-decorated liposomes showed a higher fluorescence intensity with respect to controls at pH 7.4 and 6.5 (Figure 8 and S13 in ESI).

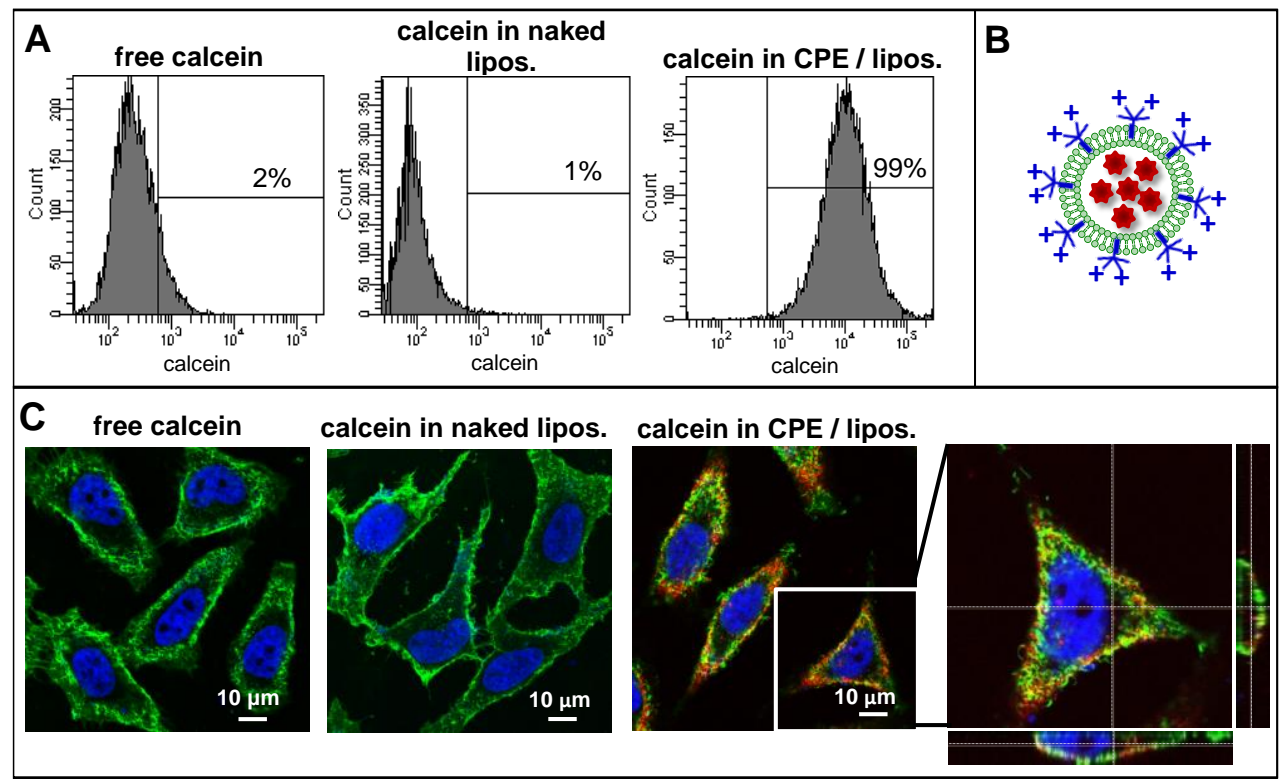

Figure 8. Cytofluorimetric profile (A) and confocal microscopic images (C) of HeLa cells incubated with free calcein, calcein loaded naked liposomes (calcein in naked lipos.) and 
liposomes decorated with 4 mol\% of $\mathrm{Arg}_{4}-\mathrm{DAG}$ (calcein in CPE/lipos.) in medium at pH 7.4. The last right image of panel (C) represents a magnification of the image of cells incubated with "calcein in CPE/lipos" and the corresponding z-stack. Cell nucleus was stained with DAPI in blue, cell membrane is represented in green upon staining with WGA-AlexaFluor 633, and calcein in red. Panel (B) schematically represents the calcein loaded liposomes.

Confocal microscopy confirmed the disposition of calcein within the cytosol when delivered by CPE-labelled liposomes (Figure 8C) while a very low cell associated fluorescence of calcein was detected neither when cells were incubated with equimolar concentration of free calcein, which was expected due to the limited cell membrane permeability of this molecule, nor when incubated with calcein loaded naked liposomes.

The cytofluorimetric data reported in Figure 9A and B show that $1 \mathrm{~h}$ incubation with BSA-Rho loaded CPE-decorated liposomes yielded 33\% fluorescently positive cells and higher mean fluorescence intensity (MFI) compared to free BSA-Rho and BSA-Rho loaded naked liposomes that showed negligible cell association and MFI. 


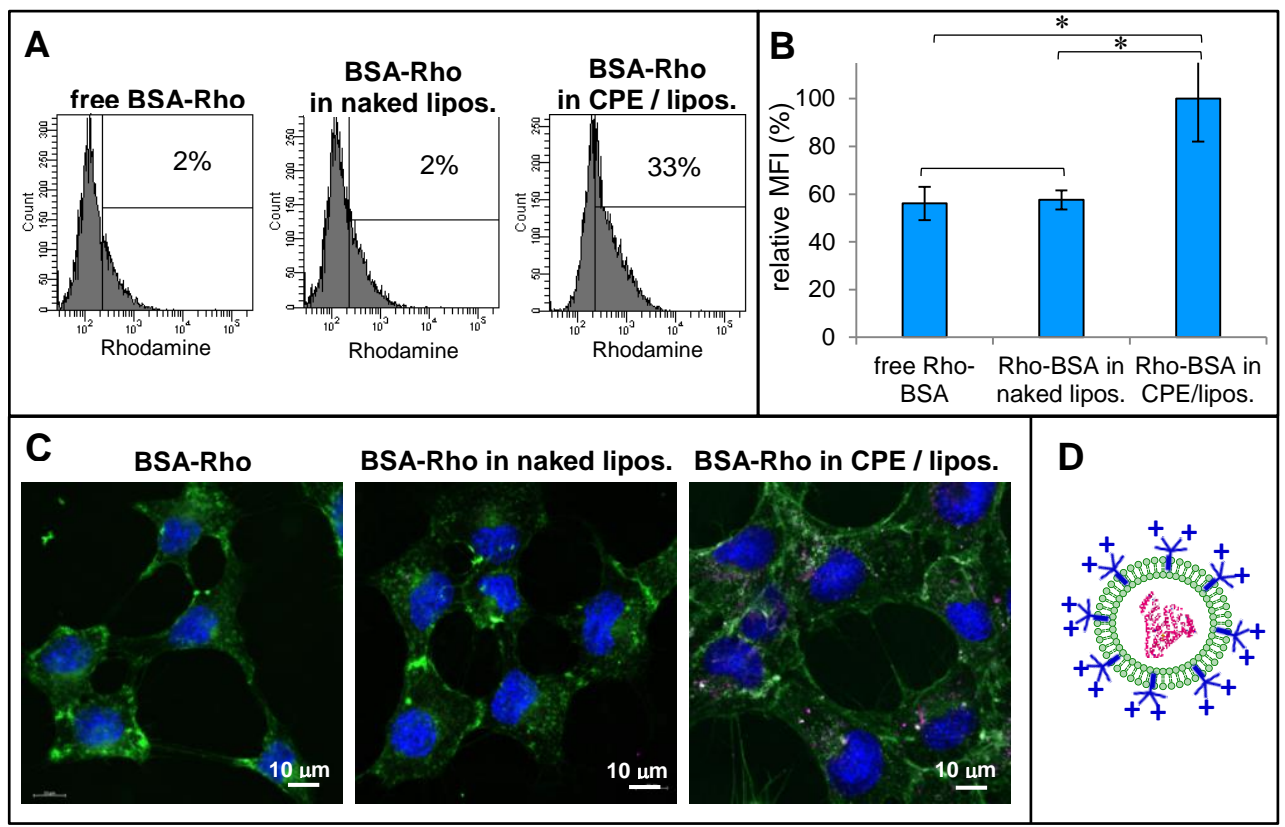

Figure 9. Cell association of BSA-Rho loaded liposomes with HeLa cells. (A) Cytofluorimetric profiles, (B) relative MFI\%, and (C) confocal microscopic images of HeLa cells treated with free BSA-Rho, naked liposomes and CPE-decorated liposomes loaded with BSA-Rho in medium at pH 7.4. Panel (D) schematically represents CPE-decorated liposomes loaded with BSA-Rho. Statistical analyses: $* \mathrm{p}<0.05 ; * * \mathrm{p}<0.01 ; * * * \mathrm{p}<0.001$.

The confocal microscopy images reported in Figure 9C show that after cell incubation with BSA-Rho loaded CPE-decorated liposomes, BSA-Rho disposed intracellularly while no intracellular fluorescence was observed by cell incubation with free BSA-Rho and BSA-Rho loaded naked liposomes. These results prove that $\mathrm{Arg}_{4}-\mathrm{DAG}$ decorated liposomes can efficiently provide for intracellular delivery of biomacromolecules. 
The different cell up-take of BSA-Rhodamine and calcein loaded Arg 4 -DAG decorated liposomes observed by cytofluorimetry and confocal microscopy (Figure 8 and 9) is ascribable to the different fluorescence quantum yield and content of the two fluorophores (rhodamine and calcein) in the formulations.

The $\mathrm{pH}$ controlled delivery of calcein to cancer cells was tested by incubating HeLa cells with calcein loaded CPE-decorated liposomes formulated with $\mathrm{mPEG}_{5 \mathrm{kDa}}-\mathrm{SDM}_{8}$ at $\mathrm{pH} 7.4$ and 6.5. The cytofluorimetric analysis indicated that the $\mathrm{pH}$-sensitive liposomes selectively delivered calcein to the cells under tumour acid environment. In fact, cells incubated with the $\mathrm{pH}$ responsive formulation at $\mathrm{pH} 7.4$ (mimicking the blood) displayed a 6.8 times lower MFI with respect to cells incubated with the same formulation at $\mathrm{pH} 6.5$ mimicking the tumour (Figure $10 \mathrm{~A}$ and $\mathrm{B})$.

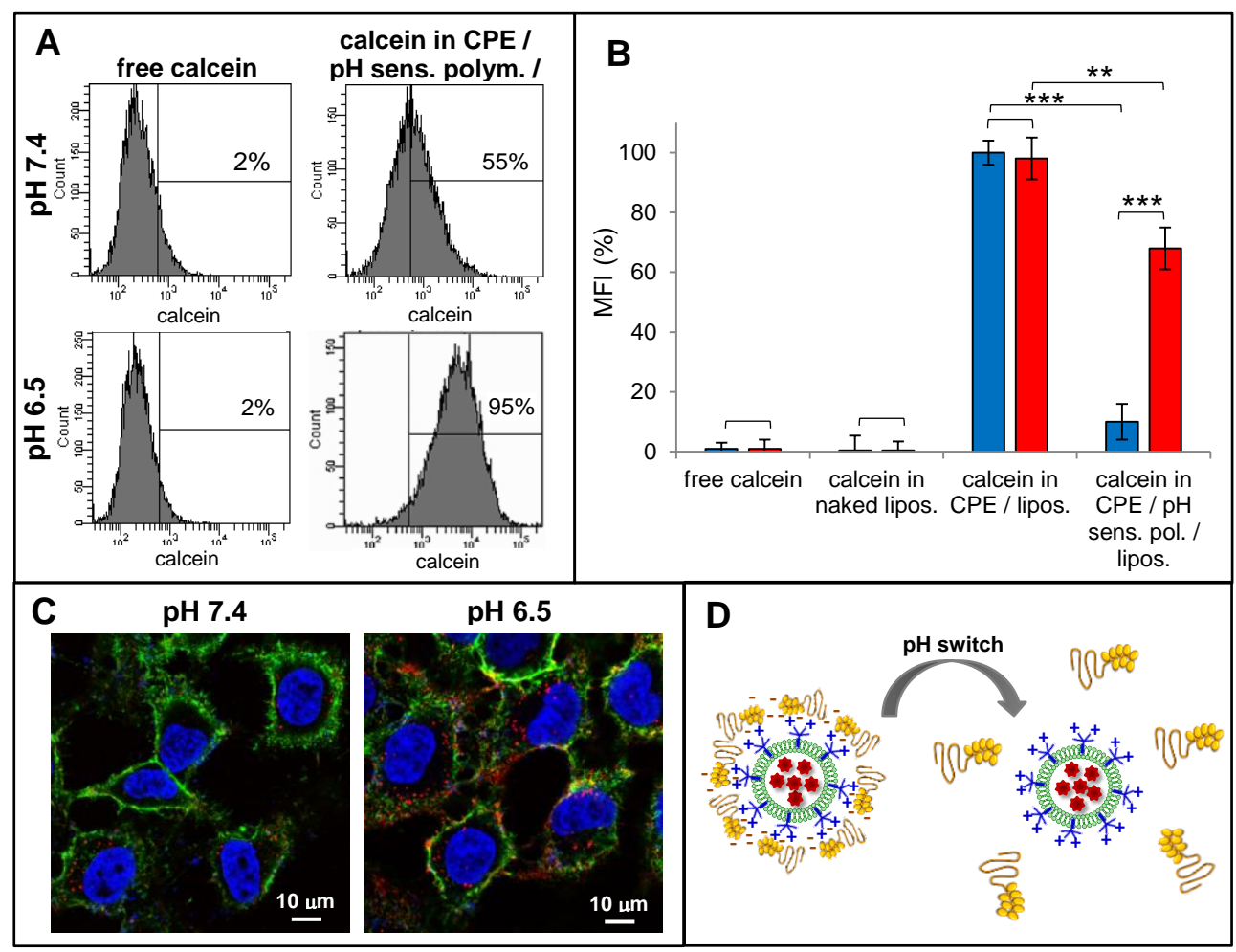

Figure 10. (A) Cytofluorimetric profiles of HeLa cells incubated with calcein-loaded CPEdecorated liposomes with and without $\mathrm{mPEG}_{5 \mathrm{kDa}}-\mathrm{SDM}_{8}$ in medium at $\mathrm{pH} 7.4$ and 6.5 (Free 
calcein was used as reference). (B) Relative MFI\% of HeLa cells at pH 7.4 ( $\square$ ) and 6.5 ( $\square$ ) from panel (A); statistical analyses: $* \mathrm{p}<0.05$; ** $\mathrm{p}<0.01$; *** $\mathrm{p}<0.001$. (C) Confocal microscopic images of HeLa cells treated with calcein loaded CPE-decorated liposomes with $\mathrm{mPEG}_{5 \mathrm{kDa}}{ }^{-}$ $\mathrm{SDM}_{8}$ at $\mathrm{pH} 7.4$ and 6.5 and schematic representation of the CPE unshielding process triggered at acid $\mathrm{pH}(\mathbf{D})$.

The confocal imaging study (Figure 10C) also confirmed that, while calcein encapsulated in the CPE-decorated liposomes remarkably disposed in the cell cytosol regardless of the incubation pH (Figure 8 and S13 in ESI), the calcein intracellular delivery by the pH responsive liposomes was higher under acidic $\mathrm{pH}(6.5)$ with respect to $\mathrm{pH} 7.4$ (Figure 10C).

These results confirmed that these $\mathrm{pH}$-sensitive liposomes are efficient vehicles for controlled and preferential intracellular delivery of loaded molecules that, otherwise, would not access the cytosol across cell membranes and can be exploited for site-selective association to and uptake by cancer cells under the tumour matrix $\mathrm{pH}$. Furthermore, the $\mathrm{pH}$-guided intracellular delivery of drugs using these $\mathrm{pH}$-sensitive liposomes may provide a valuable strategy to enhance the access to cancer cells after accumulation in the tumor while minimizing off-site toxicity to healthy tissues. Further studies are in progress to elucidate the intracellular trafficking of these liposomes and the payload release mechanism. Notably, evidences are reported in the literature that nanocarriers modified with CPPs appeared to enter the cytosol by endosomal escape. ${ }^{70}$ 


\section{Conclusions}

We have investigated here a novel strategy for site-programmed delivery of therapeutic molecules to cancer cells by combining on liposome surface a synthetic cell penetration enhancer and a polymeric $\mathrm{pH}$ sensor. These components modulate the surface features of the liposome according to a dynamic behaviour. The $\mathrm{pH}$ responsive $\mathrm{PEG}$ shielding prevents the carrier from the interaction with cells under condition mimicking the physiological environment, namely blood and extracellular environment of healthy tissues, while revealing the cell penetration enhancer on the liposome surface which guides the access of the lipidic vesicles to the cytosol of cancer cells under environmental conditions that are significant for certain diseases such as those of the tumour matrix.

The responsiveness and efficacy of the system stems from the physicochemical features of the two poly-ionic components combined on the vesicle surface and from the strategy and ratio of assembly of these functional components. Therefore, the sequential decoration of liposomes with the $\mathrm{CPE}$ and the coating with the PEGylating masking agent has allowed the generation of “smart" vesicles for site-selective drug delivery.

The results reported in this work demonstrate that the environmentally controlled shielding-andrevealing strategy can provide for enhanced cancer cell delivery of drug loaded liposomes without using active biorecognition targeting. This strategy can be applied to a variety of nanocarriers to enhance site-selectivity to the tumour. Further studies will be undertaken to elucidate the pharmacokinetic and biodistribution behaviour of this system in vivo. 


\section{ASSOCIATED CONTENT}

\section{Supporting Information.}

Supporting information include: chemicals and equipment; synthesis and characterization of the cell penetration enhancer (CPE), the $\mathrm{pH}$-sensitive copolymer and the Rhodamine labelled BSA; methods to assess decoration efficiency of liposome with Arg $_{4}-\mathrm{DAG}$ and liposome cytotoxicity; methods for liposome immobilization on SPR sensorchips and additional SPR results; SAXS spectra of control liposomes; cell association of control liposomes by FACS and confocal microscopy.

\section{AUTHOR INFORMATION}

\section{Corresponding Author}

*Stefano Salmaso,

Department of Pharmaceutical and Pharmacological Sciences, University of Padova, via F. Marzolo 5

35131 Padova - ITALY

Tel: +390498271602 , Fax: +390498275366

e-mail: stefano.salmaso@unipd.it 


\section{NOTES}

The authors declare no competing financial interest.

M.B. and A.M. contributed equally to the work.

\section{ACKNOWLEDGMENTS}

We acknowledge the University of Padova for financial support through the "Progetto di Ricerca di Ateneo" (grant N CPDA121714; CUP C94H12000020005), "Progetto strategico di ateneo (Bando 2011" C98C13002740005, PROT. STPD11RYPT_02) and Ex-60\% funding schemes. $\mathrm{AB}$ was recipient of a post-doctoral research fellowship granted by European Social Fund through Regione del Veneto (CUP N C92C16000110006, Regione del Veneto $\mathrm{N}^{\circ}$ 2105-502121-2015).

\section{REFERENCES}

(1) Szakács, G.; Paterson, J. K.; Ludwig, J. A.; Booth-Genthe, C.; Gottesman, M. M. Targeting multidrug resistance in cancer. Nature reviews Drug discovery 2006, 5 (3), 219-234.

(2) Wicki, A.; Witzigmann, D.; Balasubramanian, V.; Huwyler, J. Nanomedicine in cancer therapy: challenges, opportunities, and clinical applications. Journal of controlled release 2015, 200, 138-157.

(3) Tian, L.; Bae, Y. H. Cancer nanomedicines targeting tumor extracellular pH. Colloids and Surfaces B: Biointerfaces 2012, 99, 116-126.

(4) Tannock, I. F.; Rotin, D. Acid pH in tumors and its potential for therapeutic exploitation. Cancer research 1989, 49 (16), 4373-4384.

(5) Norton, K.-A.; Popel, A. S.; Pandey, N. B. Heterogeneity of chemokine cell-surface receptor expression in triple-negative breast cancer. American journal of cancer research 2015, 5 (4), 1295-1307. 
(6) Veiseh, M.; Kwon, D. H.; Borowsky, A. D.; Tolg, C.; Leong, H. S.; Lewis, J. D.; Turley, E. A.; Bissell, M. J. Cellular heterogeneity profiling by hyaluronan probes reveals an invasive but slow-growing breast tumor subset. Proceedings of the National Academy of Sciences 2014, 111 (17), E1731-E1739.

(7) Schraa, A. J.; Kok, R. J.; Berendsen, A. D.; Moorlag, H. E.; Bos, E. J.; Meijer, D. K.; de Leij, L. F.; Molema, G. Endothelial cells internalize and degrade RGD-modified proteins developed for tumor vasculature targeting. Journal of controlled release 2002, 83 (2), 241-251.

(8) Nath, A. Human immunodeficiency virus (HIV) proteins in neuropathogenesis of HIV dementia. The Journal of infectious diseases 2002, 186 (Supplement_2), S193-S198.

(9) Sawant, R. R.; Patel, N. R.; Torchilin, V. P. Therapeutic delivery using cell-penetrating peptides. European Journal of Nanomedicine 2013, 5 (3), 141-158.

(10) Farkhani, S. M.; Valizadeh, A.; Karami, H.; Mohammadi, S.; Sohrabi, N.; Badrzadeh, F. Cell penetrating peptides: efficient vectors for delivery of nanoparticles, nanocarriers, therapeutic and diagnostic molecules. Peptides 2014, 57, 78-94.

(11) Koren, E.; Torchilin, V. P. Cell-penetrating peptides: breaking through to the other side. Trends in molecular medicine 2012, 18 (7), 385-393.

(12) Madani, F.; Lindberg, S.; Langel, Ü.; Futaki, S.; Gräslund, A. Mechanisms of cellular uptake of cell-penetrating peptides. Journal of Biophysics 2011, 2011.

(13) Verdurmen, W. P.; Wallbrecher, R.; Schmidt, S.; Eilander, J.; Bovee-Geurts, P.; Fanghänel, S.; Bürck, J.; Wadhwani, P.; Ulrich, A. S.; Brock, R. Cell surface clustering of heparan sulfate proteoglycans by amphipathic cell-penetrating peptides does not contribute to uptake. Journal of controlled release 2013, 170 (1), 83-91.

(14) Wallbrecher, R.; Verdurmen, W. P.; Schmidt, S.; Bovee-Geurts, P. H.; Broecker, F.; Reinhardt, A.; van Kuppevelt, T. H.; Seeberger, P. H.; Brock, R. The stoichiometry of peptideheparan sulfate binding as a determinant of uptake efficiency of cell-penetrating peptides. Cellular and molecular life sciences 2014, 71 (14), 2717-2729.

(15) Schmidt, N.; Mishra, A.; Lai, G. H.; Wong, G. C. Arginine-rich cell-penetrating peptides. FEBS letters 2010, 584 (9), 1806-1813.

(16) Su, Y.; Waring, A. J.; Ruchala, P.; Hong, M. Membrane-bound dynamic structure of an arginine-rich cell-penetrating peptide, the protein transduction domain of HIV TAT, from solidstate NMR. Biochemistry 2010, 49 (29), 6009-6020.

(17) Eiríksdóttir, E.; Konate, K.; Langel, Ü.; Divita, G.; Deshayes, S. Secondary structure of cellpenetrating peptides controls membrane interaction and insertion. Biochimica et Biophysica Acta (BBA)-Biomembranes 2010, 1798 (6), 1119-1128.

(18) Palm, C.; Jayamanne, M.; Kjellander, M.; Hällbrink, M. Peptide degradation is a critical determinant for cell-penetrating peptide uptake. Biochimica et Biophysica Acta (BBA)Biomembranes 2007, 1768 (7), 1769-1776.

(19) Grunwald, J.; Rejtar, T.; Sawant, R.; Wang, Z.; Torchilin, V. P. TAT peptide and its conjugates: proteolytic stability. Bioconjugate chemistry 2009, 20 (8), 1531-1537.

(20) Wike-Hooley, J.; Haveman, J.; Reinhold, H. The relevance of tumour $\mathrm{pH}$ to the treatment of malignant disease. Radiotherapy and Oncology 1984, 2 (4), 343-366.

(21) Barnard, A.; Posocco, P.; Pricl, S.; Calderon, M.; Haag, R.; Hwang, M. E.; Shum, V. W.; Pack, D. W.; Smith, D. K. Degradable self-assembling dendrons for gene delivery: experimental and theoretical insights into the barriers to cellular uptake. Journal of the American Chemical Society 2011, 133 (50), 20288-20300. 
(22) Ravazzolo, E.; Salmaso, S.; Mastrotto, F.; Bersani, S.; Gallon, E.; Caliceti, P. pH-responsive lipid core micelles for tumour targeting. European Journal of Pharmaceutics and

Biopharmaceutics 2013, 83 (3), 346-357.

(23) Bangham, A.; Standish, M. M.; Watkins, J. C. Diffusion of univalent ions across the lamellae of swollen phospholipids. Journal of molecular biology 1965, 13 (1), 238-IN27. (24) Marianecci, C.; Di Marzio, L.; Del Favero, E.; Cantù, L.; Brocca, P.; Rondelli, V.; Rinaldi, F.; Dini, L.; Serra, A.; Decuzzi, P. Niosomes as drug nanovectors: multiscale pH-dependent structural response. Langmuir 2016, 32 (5), 1241-1249.

(25) Sandri, G.; Motta, S.; Bonferoni, M. C.; Brocca, P.; Rossi, S.; Ferrari, F.; Rondelli, V.; Cantù, L.; Caramella, C.; Del Favero, E. Chitosan-coupled solid lipid nanoparticles: tuning nanostructure and mucoadhesion. European Journal of Pharmaceutics and Biopharmaceutics 2017, 110, 13-18.

(26) Granqvist, N.; Yliperttula, M.; Välimäki, S.; Pulkkinen, P.; Tenhu, H.; Viitala, T. Control of the morphology of lipid layers by substrate surface chemistry. Langmuir 2014, 30 (10), 27992809.

(27) Torres, A. G.; Milflores-Flores, L.; Garcia-Gallegos, J. G.; Patel, S. D.; Best, A.; La Ragione, R. M.; Martinez-Laguna, Y.; Woodward, M. J. Environmental regulation and colonization attributes of the long polar fimbriae (LPF) of Escherichia coli O157: H7. International Journal of Medical Microbiology 2007, 297 (3), 177-185.

(28) Sawant, R. M.; Hurley, J.; Salmaso, S.; Kale, A.; Tolcheva, E.; Levchenko, T.; Torchilin, V. "SMART" drug delivery systems: double-targeted $\mathrm{pH}$-responsive pharmaceutical nanocarriers. Bioconjugate chemistry 2006, 17 (4), 943-949.

(29) Sethuraman, V. A.; Bae, Y. H. TAT peptide-based micelle system for potential active targeting of anti-cancer agents to acidic solid tumors. Journal of Controlled Release 2007, 118 (2), 216-224.

(30) Lee, E. S.; Gao, Z.; Kim, D.; Park, K.; Kwon, I. C.; Bae, Y. H. Super pH-sensitive multifunctional polymeric micelle for tumor pHe specific TAT exposure and multidrug resistance. Journal of Controlled Release 2008, 129 (3), 228-236.

(31) Matsumura, Y.; Maeda, H. A new concept for macromolecular therapeutics in cancer chemotherapy: mechanism of tumoritropic accumulation of proteins and the antitumor agent smancs. Cancer research 1986, 46 (12 Part 1), 6387-6392.

(32) Salmaso, S.; Caliceti, P. Stealth properties to improve therapeutic efficacy of drug nanocarriers. Journal of drug delivery 2013, 2013.

(33) Sung, M.; Poon, G. M.; Gariépy, J. The importance of valency in enhancing the import and cell routing potential of protein transduction domain-containing molecules. Biochimica et Biophysica Acta (BBA)-Biomembranes 2006, 1758 (3), 355-363.

(34) Sheldon, K.; Liu, D.; Ferguson, J.; Gariepy, J. Loligomers: design of de novo peptide-based intracellular vehicles. Proceedings of the National Academy of Sciences 1995, 92 (6), 2056-2060. (35) Feliu, N.; Walter, M. V.; Montañez, M. I.; Kunzmann, A.; Hult, A.; Nyström, A.; Malkoch, M.; Fadeel, B. Stability and biocompatibility of a library of polyester dendrimers in comparison to polyamidoamine dendrimers. Biomaterials 2012, 33 (7), 1970-1981.

(36) Wender, P. A.; Mitchell, D. J.; Pattabiraman, K.; Pelkey, E. T.; Steinman, L.; Rothbard, J. B. The design, synthesis, and evaluation of molecules that enable or enhance cellular uptake: peptoid molecular transporters. Proceedings of the National Academy of Sciences 2000, 97 (24), 13003-13008. 
(37) Yoon, Y.-R.; Lim, Y.-b.; Lee, E.; Lee, M. Self-assembly of a peptide rod-coil: a polyproline rod and a cell-penetrating peptide Tat coil. Chemical Communications 2008, (16), 1892-1894.

(38) Na, K.; Lee, K. H.; Bae, Y. H. pH-sensitivity and pH-dependent interior structural change of self-assembled hydrogel nanoparticles of pullulan acetate/oligo-sulfonamide conjugate. Journal of Controlled Release 2004, 97 (3), 513-525.

(39) Kang, S. I.; Bae, Y. H. pH-induced solubility transition of sulfonamide-based polymers. Journal of controlled release 2002, 80 (1-3), 145-155.

(40) Sethuraman, V. A.; Na, K.; Bae, Y. H. pH-responsive sulfonamide/PEI system for tumor specific gene delivery: an in vitro study. Biomacromolecules 2006, 7 (1), 64-70.

(41) Awasthi, V.; Garcia, D.; Klipper, R.; Goins, B.; Phillips, W. Neutral and anionic liposomeencapsulated hemoglobin: effect of postinserted poly (ethylene glycol)-

distearoylphosphatidylethanolamine on distribution and circulation kinetics. Journal of Pharmacology and Experimental Therapeutics 2004, 309 (1), 241-248.

(42) Iden, D. L.; Allen, T. M. In vitro and in vivo comparison of immunoliposomes made by conventional coupling techniques with those made by a new post-insertion approach. Biochimica et Biophysica Acta (BBA)-Biomembranes 2001, 1513 (2), 207-216.

(43) Torchilin, V. P. Cell penetrating peptide-modified pharmaceutical nanocarriers for intracellular drug and gene delivery. Peptide Science 2008, 90 (5), 604-610.

(44) Koren, E.; Apte, A.; Jani, A.; Torchilin, V. P. Multifunctional PEGylated 2C5immunoliposomes containing $\mathrm{pH}$-sensitive bonds and TAT peptide for enhanced tumor cell internalization and cytotoxicity. Journal of controlled release 2012, 160 (2), 264-273.

(45) Pappalardo, J. S.; Langellotti, C. A.; Di Giacomo, S.; Olivera, V.; Quattrocchi, V.; Zamorano, P. I.; Hartner, W. C.; Levchenko, T. S.; Torchilin, V. P. In vitro transfection of bone marrow-derived dendritic cells with TATp-liposomes. International journal of nanomedicine 2014, 9, 963-973.

(46) SAKAGUCHI, S. ÜBER DIE KATALYTISCHE WIRKUNG DES BLUTFARBSTOFFES AUF NATRIUMHYPOCHLORIT NEBST EINER NEUEN FARBENREAKTION DES BLUTES. The Journal of Biochemistry 1925, 5 (1), 13-24.

(47) Yang, S.-T.; Zaitseva, E.; Chernomordik, L. V.; Melikov, K. Cell-penetrating peptide induces leaky fusion of liposomes containing late endosome-specific anionic lipid. Biophysical journal 2010, 99 (8), 2525-2533.

(48) Fitch, C. A.; Platzer, G.; Okon, M.; Garcia-Moreno, E.; McIntosh, L. P. Arginine: its pKa value revisited. Protein Science 2015, 24 (5), 752-761.

(49) Lee, S.-M.; Ahn, R. W.; Chen, F.; Fought, A. J.; O’halloran, T. V.; Cryns, V. L.; Nguyen, S. T. Biological evaluation of $\mathrm{pH}$-responsive polymer-caged nanobins for breast cancer therapy. ACS nano 2010, 4 (9), 4971-4978.

(50) Mills, T. T.; Huang, J.; Feigenson, G. W.; Nagle, J. F. Effects of cholesterol and unsaturated DOPC lipid on chain packing of saturated gel-phase DPPC bilayers. General physiology and biophysics 2009, 28 (2), 126-139.

(51) Nakamura, K.; Yamashita, K.; Itoh, Y.; Yoshino, K.; Nozawa, S.; Kasukawa, H.

Comparative studies of polyethylene glycol-modified liposomes prepared using different PEGmodification methods. Biochimica et Biophysica Acta (BBA)-Biomembranes 2012, 1818 (11), 2801-2807.

(52) Löfås, S.; Johnsson, B. A novel hydrogel matrix on gold surfaces in surface plasmon resonance sensors for fast and efficient covalent immobilization of ligands. Journal of the Chemical Society, Chemical Communications 1990, (21), 1526-1528. 
(53) Kari, O. K.; Rojalin, T.; Salmaso, S.; Barattin, M.; Jarva, H.; Meri, S.; Yliperttula, M.; Viitala, T.; Urtti, A. Multi-parametric surface plasmon resonance platform for studying liposome-serum interactions and protein corona formation. Drug delivery and translational research 2017, 7 (2), 228-240.

(54) Connors, K. A. Binding constants: the measurement of molecular complex stability, WileyInterscience: 1987.

(55) Tinoco, I.; Sauer, K.; Wang, J. C. Physical chemistry: principles and applications in biological sciences, 1995.

(56) Caracciolo, G.; Callipo, L.; De Sanctis, S. C.; Cavaliere, C.; Pozzi, D.; Laganà, A. Surface adsorption of protein corona controls the cell internalization mechanism of DC-CholDOPE/DNA lipoplexes in serum. Biochimica et Biophysica Acta (BBA)-Biomembranes 2010, $1798(3), 536-543$.

(57) Yang, S.-y.; Zheng, Y.; Chen, J.-y.; Zhang, Q.-y.; Zhao, D.; Han, D.-e.; Chen, X.-j.

Comprehensive study of cationic liposomes composed of DC-Chol and cholesterol with different mole ratios for gene transfection. Colloids and Surfaces B: Biointerfaces 2013, 101, 6-13.

(58) Moghimi, S. M.; Muir, I.; Illum, L.; Davis, S. S.; Kolb-Bachofen, V. Coating particles with a block co-polymer (poloxamine-908) suppresses opsonization but permits the activity of dysopsonins in the serum. Biochimica et Biophysica Acta (BBA)-Molecular Cell Research 1993, 1179 (2), 157-165.

(59) Nag, O. K.; Awasthi, V. Surface engineering of liposomes for stealth behavior.

Pharmaceutics 2013, 5 (4), 542-569.

(60) Anderson, M.; Moshnikova, A.; Engelman, D. M.; Reshetnyak, Y. K.; Andreev, O. A. Probe for the measurement of cell surface $\mathrm{pH}$ in vivo and ex vivo. Proceedings of the National Academy of Sciences 2016, 113 (29), 8177-8181.

(61) Roursgaard, M.; Knudsen, K. B.; Northeved, H.; Persson, M.; Christensen, T.; Kumar, P. E.; Permin, A.; Andresen, T. L.; Gjetting, T.; Lykkesfeldt, J. In vitro toxicity of cationic micelles and liposomes in cultured human hepatocyte (HepG2) and lung epithelial (A549) cell lines.

Toxicology in Vitro 2016, 36, 164-171.

(62) Sarker, S. R.; Aoshima, Y.; Hokama, R.; Inoue, T.; Sou, K.; Takeoka, S. Arginine-based cationic liposomes for efficient in vitro plasmid DNA delivery with low cytotoxicity.

International journal of nanomedicine 2013, 8, 1361-1375.

(63) Romøren, K.; Thu, B. J.; Bols, N. C.; Evensen, Ø. Transfection efficiency and cytotoxicity of cationic liposomes in salmonid cell lines of hepatocyte and macrophage origin. Biochimica et Biophysica Acta (BBA)-Biomembranes 2004, 1663 (1), 127-134.

(64) Xu, Y.; Szoka, F. C. Mechanism of DNA release from cationic liposome/DNA complexes used in cell transfection. Biochemistry 1996, 35 (18), 5616-5623.

(65) Shimanouchi, T.; Ishii, H.; Yoshimoto, N.; Umakoshi, H.; Kuboi, R. Calcein permeation across phosphatidylcholine bilayer membrane: effects of membrane fluidity, liposome size, and immobilization. Colloids and Surfaces B: Biointerfaces 2009, 73 (1), 156-160.

(66) Yang, N. J.; Hinner, M. J. Getting across the cell membrane: an overview for small molecules, peptides, and proteins. In Site-Specific Protein Labeling; Springer: 2015; pp 29-53. (67) Vila-Caballer, M.; Codolo, G.; Munari, F.; Malfanti, A.; Fassan, M.; Rugge, M.; Balasso, A.; de Bernard, M.; Salmaso, S. A pH-sensitive stearoyl-PEG-poly (methacryloyl sulfadimethoxine)-decorated liposome system for protein delivery: an application for bladder cancer treatment. Journal of Controlled Release 2016, 238, 31-42. 
(68) Charbonneau, D. M.; Tajmir-Riahi, H.-A. Study on the interaction of cationic lipids with bovine serum albumin. The Journal of Physical Chemistry B 2009, 114 (2), 1148-1155.

(69) Colletier, J.-P.; Chaize, B.; Winterhalter, M.; Fournier, D. Protein encapsulation in liposomes: efficiency depends on interactions between protein and phospholipid bilayer. $B M C$ biotechnology 2002, 2 (1), 9.

(70) Nativo, P.; Prior, I. A.; Brust, M. Uptake and intracellular fate of surface-modified gold nanoparticles. ACS nano 2008, 2 (8), 1639-1644. 


\section{TABLE OF CONTENTS}

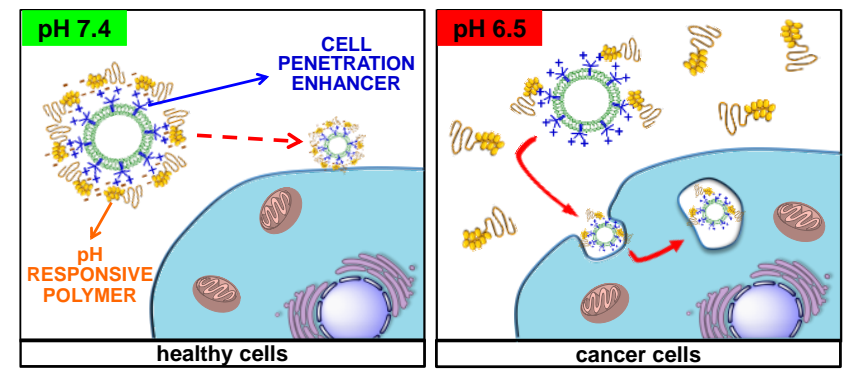

